\title{
Statistical Thermodynamics of the Substitutional Short-Range Atomic Order and Kinematics of the Diffuse Scattering of Radiations in (Para)Magnetic F.C.C.-Ni-Fe Alloys
}

\author{
S. M. Bokoch ${ }^{1,4}$, V. A. Tatarenko ${ }^{2}$, and I. V. Vernyhora ${ }^{2,3}$ \\ ${ }^{1}$ Institute for Advanced Materials Science and Innovative Technologies, \\ Department of Materials Design and Technology, \\ 15 Sauletekio Ave., \\ LT-10224 Vilnius, Lithuania \\ ${ }^{2}$ G.V.Kurdyumov Institute for Metal Physics, N.A.S. of Ukraine, \\ Department of Solid State Theory, \\ 36 Academician Vernadsky Blvd., \\ UA-03680 Kyyiv-142, Ukraine \\ ${ }^{3}$ Institute for Applied Physics, N.A.S. of Ukraine, \\ Department of Modelling of Radiation Effects \\ and Microstructure Transformations in Constructional Materials, \\ 58 Petropavlivska Str., \\ UA-40030 Sumy, Ukraine \\ ${ }^{4}$ NIK Electronics, \\ 34 Lesi Ukrayinky Blvd., \\ UA-01601 Kyyiv, Ukraine
}

In imitation of f.c.c.-Ni-Fe alloy, the statistical-thermodynamic approach is applied for quantitative analysis of the thermal and composition-magnetic moment fluctuations' influence on the kinematic diffuse-scattering intensity of radiations (X-rays or thermal neutrons) in magnetic alloys with the atomic short-range order (SRO). Within the temperature-concentration $(T-c)$ domains of macroscopically ferromagnetic and paramagnetic states of f.c.c. alloy, the relation for the diffuse-scattering intensity distribution over the quasi-wave vectors (including the Bragg's 'fundamental' point), depending on the total 'mixing' energies of atoms, are obtained within the scope of (i) the selfconsistent-field (SCF) and mean-SCF (MSCF) approximations as well as (ii) the simplest approximation by 'interpolation'. The $2 D$ patterns of $(001) *$-type diffuse-scattering intensity distribution over a reciprocal space as well as the corresponding distributions (local configurations) of $\mathrm{Fe}$ and $\mathrm{Ni}$ atoms over the f.c.c.-lattice sites are modelled by a statistical Monte Carlo technique using the available experimental data on the Warren-Cowley SRO parameters extracted. Taking into account the magnetic ('exchange') interactions of atoms within the 
statistical thermodynamics of alloys with the atomic SRO, it is possible to clarify the significant $(T-c)$-deviations of the diffuse-scattering intensity from its values corresponding to classical relation by the Krivoglaz-Clapp-Moss (KCM) formula with constant interatomic-interaction parameters. The principal possibilities and validity of using the generalized form and main assumptions of the KCM formula under an analysis of the diffuse-scattering intensity in magnetic alloys are ascertained. One of the intriguing findings of a given work belongs to revealing a possibility for simple and quite accurate estimation of the total 'mixing' energies, including their magnetic and nonmagnetic contributions, by means of the experimental SRO intensities for magnetic alloys obtained with Xray diffraction techniques only applied for synchrotron radiation instrumentation instead of conventional neutron scattering techniques, which are commonly used as a powerful probe in physics of magnetic materials. Obtained analytical and computational results on diffuse scattering characterization of (para)magnetic f.c.c.-Ni-Fe alloys are in a decent fit with all the reliable X-ray and thermal neutron diffraction data collected over years.

На прикладі стопу ГЦК-Ni-Fe застосовано статистично-термодинамічний підхід до чисельної аналізи впливу термічних і концентраційно-магнетних флюктуацій на інтенсивність кінематичного дифузного розсіяння випромінення (Рентгенових променів або теплових невтронів) у атомарно невпорядкованих (з близьким порядком (БП)) магнетних стопах. У рамках (а) наближень самоузгодженого (СУП) та середнього самоузгодженого (ССУП) полів і (б) найпростішої «інтерполяційної» апроксимації одержано вираз для розподілу інтенсивности дифузного розсіяння по квазихвильових векторах (в тому числі й для Брег'гвої «фундаментальної» точки) залежно від повних енергій «змішання» атомів ГЦК-стопу у температурно-концентраційних $(T-c)$ областях його макроскопічно феромагнетного та парамагнетного станів. 3 використанням статистичної методи Монте-Карло та приступних експериментальних даних про параметри БП Уоррена-Кавлі змодельовано $2 D$-картини розподілу інтенсивности дифузного розсіяння у площинах типу (001)* оберненого простору та відповідне розміщення (локальні конфігурації) атомів $\mathrm{Fe}$ й $\mathrm{Ni}$ по вузлах. Врахування магнетних («обмінних») взаємодій атомів у статистичній термодинаміці стопів з атомним БП прояснює значні $T-c$-відхили інтенсивности дифузного розсіяння від значень, що відповідають клясичному виразу для неї за формулою Кривоглаза-КлеппаМосса (ККМ) зі сталими параметрами міжатомових взаємодій. 3'ясовано принципові можливості й обгрунтованість використання узагальненої форми та основних припущень формули ККМ для аналізи інтенсивности дифузного розсіяння у магнетних стопах. Одним з результатів даної роботи $€$ встановлення можливости простого та достатньо точного оцінювання повних енергій «змішання» із врахуванням магнетних і немагнетних внесків за експериментальними БП-інтенсивностями для магнетних стопів, визначеними із застосуванням лише Рентгенових дифракційних методик для синхротронної міряльної апаратури замість традиційних методик невтронного розсіяння, яких зазвичай використовують для діягностики магнетовпорядкованих матеріялів. Представлені аналітичні та розрахункові результати стосовно дифузного розсіяння у (пара)магнетних стопах ГЦК-Ni-Fe узгоджуються з надійними даними мірянь дифракції Рентгенових променів i теплових невтронів, яких було накопичено впродовж багатьох років. 
На примере сплава ГЦК-Ni-Fe применён статистико-термодинамический подход к численному анализу влияния термических и концентрационномагнитных флюктуаций на интенсивность кинематического диффузного рассеяния излучений (рентгеновских лучей или тепловых нейтронов) в атомно неупорядоченных (с ближним порядком (БП)) магнитных сплавах. В рамках (а) приближений самосогласованного (ССП) и среднего самосогласованного (СССП) полей и (б) простейшей «интерполяционной» аппроксимации получено выражение для распределения интенсивности диффузного рассеяния по квазиволновым векторам (в том числе и для брэгговской «фундаментальной» точки) в зависимости от полных энергий «смешения» атомов ГЦК-сплава в температурно-концентрационных $(T-c)$ областях его макроскопически ферромагнитного и парамагнитного состояний. С использованием статистического метода Монте-Карло и доступных экспериментальных данных о параметрах БП Уоррена-Каули смоделированы 2Dкартины распределения интенсивности диффузного рассеяния в плоскостях типа $(001) *$ обратного пространства и соответствующее пространственное размещение (локальные конфигурации) атомов $\mathrm{Fe}$ и $\mathrm{Ni}$ на узлах. Учёт магнитных («обменных») взаимодействий атомов в статистической термодинамике сплавов с атомным БП проясняет значительные $T-c$-отклонения интенсивности диффузного рассеяния от значений, соответствующих классическому выражению для неё по формуле Кривоглаза-Клэппа-Мосса (ККМ) с постоянными параметрами межатомных взаимодействий. Выяснены принципиальные возможности и обоснованность использования обобщённой формы и основных предположений формулы ККМ для анализа интенсивности диффузного рассеяния в магнитных сплавах. Одним из результатов данной работы является установление возможности простого и достаточно точного оценивания полных энергий «смешения» при учёте магнитных и немагнитных вкладов на основе экспериментальных БП-интенсивностей для магнитных сплавов, определённых с применением только рентгеновских дифракционных методик для синхротронной измерительной аппаратуры вместо традиционных методик нейтронного рассеяния, которые обычно используются для диагностики магнитоупорядоченных материалов. Представленные аналитические и численные результаты о диффузном рассеянии в (пара)магнитных сплавах ГЦК-Ni-Fe согласуются с надёжными данными измерений дифракции рентгеновских лучей и тепловых нейтронов, накопленными за многие годы.

Keywords: f.c.c.-Ni-Fe alloys, interatomic interactions, magnetic impurity interactions, short-range atomic ordering, diffuse scattering, statistical thermodynamics, Monte Carlo simulation.

(Received 7 March, 2012; in final version 19 September, 2012)

\section{INTRODUCTION}

Nowadays, metallic alloys take one of the leading places in materials science and advanced technological applications due to their strength, heat resistance, electro- and thermal conductivities, specific optical 
and magnetic properties, an occurrence of superconductive state, etc. The whole spectrum of these physical properties is closely related with the microscopic (crystal-lattice symmetry, point defects, static and dynamic crystal-lattice imperfections, etc.), mesoscopic (nanoscale formations, defects clusters, etc.) and macroscopic (phase composition, size, shape and spatial distribution of inclusions, etc.) structures of the system at issue [1-7]. On the other hand, the majority of the equilibrium microscopic structural states and the nonequilibrium processes controlled by kinetics of both the structural and magnetic phase transformations are determined mostly by the interatomic-interaction energies (including magnetic ('exchange') ones), namely, appropriate interchange ('mixing') energies of atoms, in such mixed systems. Undoubtedly, it is evident that the exhaustive knowledge and detailed understanding of both the microscopic parameters for (para)magnetic interatomic-interaction energies and the configuration part of the thermodynamical potentials (such as the Helmholtz free energy) of certain (dis)ordered phases are crucial for the self-consistent determination of the 'nature' and precise prediction of many thermodynamic and kinetic properties of solid alloys.

Thus, due to its importance, many researchers have been attracted to this field, and, as a result, a set of outstanding experimental findings $[8,9]$ as well as theoretical ones [1-7, 10-61] have appeared for the last decades. Moreover, both the classical (semi-phenomenological) theoretical descriptions [10-19, 29-61] and ab initio electronic structure calculations (based on quantum-mechanical first principles) [20-28] were found to be remarkably fruitful. It is also worth noting that all these theoretical achievements were stimulated by many impressive results of experimental works on an 'elastic' interaction of radiations (X-rays or thermal neutrons) with disordered condensed matter [6-9] (for details, see also references therein). Consequently, to date, one of the unique experimental methods, which enables to extract theoretically the quantitative information about 'mixing' energies of atoms in alloys, is referred to as the 'elastic' diffuse scattering of radiations from disordered solid solutions [6-9]. The interrelation between the diffuse scattering intensities in atomically disordered solid solutions and the 'mixing'-energies' Fourier components has been proposed theoretically for the first time by Krivoglaz (1957) [10] and later by Clapp and Moss (1966-1968) [11-13]. Nowadays, this famous relation is widely known as the KCM formula. Using the KCM formula in its original form and within the scope of its main approximations (independence of 'mixing' energies on concentration and temperature), it is possible to evaluate the 'natural' temperature and concentration dependences of the diffuse scattering intensities (see below) or evaluate the 'mixing' energies on the basis of known experimental data on diffuse scattering intensities. However, in many practical cases, the situation becomes complicated 
due to the presence of several anomalies in the experimental diffuse scattering patterns such as the concentration- and temperature-induced diffuse intensity splitting [8] near the Lifshitz high-symmetry points within the first Brillouin zone $\left(1^{\text {st }} B Z\right)$ in reciprocal space of a host crystal lattice, their 'unusual' temperature and concentration dependences, etc. In order to explain these features, a number of improved approximations were developed, in particular, considering the manybody interatomic-interactions' effects, interatomic correlation phenomena, etc. In fact, as will be shown below, the absence of a proper understanding of some above-mentioned diffuse scattering anomalies was the main reason for numerous critiques addressed to the conventional 'pairwise' interatomic-interaction models in mixed solids as well as to the KCM approximation for some metallic alloys. To our knowledge, the most fruitful theoretical methods are as follow: Tahir-Kheli method [14], cluster variation method (CVM) [15-17], spherical model (SM) $[18,19]$, Onsager cavity field (OCF) method [20,21] and other advanced first-principles approaches [22-28], inverse Monte Carlo (IMC) [29] method and its linearized (LIMC) [30] version, Vaks-Zein-Kamyshenko cluster-field (CF) approach [31-33], Tokar-Masanskii-Grishchenko theory (based on the 'gamma' expansion method (GEM)) [34-37], alphaexpansion (AE) methods including high-temperature methods (HTM) [38-41]. Also, a series of quite new approaches was developed on the basis of the so-called 'ring' approximation [42-55] and recently on the basis of the self-consistent-field (SCF) and mean-SCF (MSCF) approximations' approach (taking into account strong interrelations between magnetic and atomic subsystems of an alloy) [56-61]. All these methodologies for evaluations of the interatomic 'mixing' energies (diffuse intensities) can be naturally subdivided into two groups: (i) the reciprocal-space representation methods (i.e. in $\mathrm{k}$-space) [10-14, 18-28, 4261] and (ii) the direct-space representation approximations (i.e. in $\mathbf{r}$ space) [15-17, 29-41]. It is clear that the main disadvantage of the latter methods is the restriction of the extent of interatomic-interaction energies to the finite number of coordination shells due to considering of a limited number of Warren-Cowley SRO parameters, $\alpha\left(\mathbf{r}_{l m n}\right)$ (where $l, m$, and $n$ denote the conventional Miller's indices). This shortcoming disappears, if one employs the methods developed for the infinite radius of interaction energies (i.e. within the Fourier representation). In case of alloys with a short-range interatomic-interaction nature, for example, such as the 'exchange' magnetic interaction, the results of both $\mathbf{k}$-space approach and $\mathbf{r}$-space one are almost identical.

In a given work, in imitation of f.c.c. $-\mathrm{Ni}_{1-c} \mathrm{Fe}_{c}$ alloy, a simple and accurate as well as physically understandable statistical-thermodynamics model of the atomic SRO states for (para)magnetic substitutional alloys with two magnetic constituents is developed (Sec. 2). The model is based on classical statistical-mechanics approximations only (i.e. SCF + MSCF 
[56-61]), which assume the 'pairwise' interatomic and magnetic interactions solely, neglecting the interatomic correlation and many-body interaction effects. Along with such analytic description, as an alternative, we also consider an 'interpolating' approximation, assuming the ( $3^{\text {rd }}$ order) polynomial temperature dependence of the total 'mixing'energies' Fourier components in the $(T-c)$-domain of a macroscopically ferromagnetic alloy. Thus, within the scope of both considerations, the relations for the diffuse scattering intensity are obtained, and, as a result, similar ones can be applied in general to any magnetically (dis)ordered substitutional solid solutions with the atomic SRO. The main results and their discussion are presented in Sec. 3. In particular, here, the Monte Carlo (MC) simulations are carried out, using the literature data on the experimentally obtained values of Warren-Cowley SRO parameters for disordered f.c.c.-Ni-Fe alloy (at different compositions and annealing temperatures). In addition, the modelled local atomic configurations in a real space and their Fourier transforms (diffuse scattering intensity patterns in a reciprocal space) are thoroughly analysed. In addition, both the rigorous statistical-thermodynamics and 'interpolating' approximations are applied for calculations of the $(T-c)$-dependences of the diffuse scattering intensities for two dominant quasi-wave vectors $\mathbf{k}$ within the $1^{\text {st }} B Z$, namely, superstructural $\mathbf{k}_{X}(001)$ point and 'fundamental' Bragg's $\mathbf{k}_{\Gamma}(000)$ one for disordered (para)magnetic f.c.c.-Ni-Fe solid solution. In conclusion of Sec. 3, the available models and theories, which were applied before for the estimation of interatomic-interaction energies and diffuse scattering patterns for f.c.c.-Ni-Fe alloy, are critically analysed. The summary and perspectives of a given work are presented in Sec. 4. Finally, we would like to emphasize that, here, we will not discuss the diffuse scattering intensities' distribution over the reciprocal space in details as well as the 'mixing' energies' Fourier components symmetry behaviour near the 'fundamental' Bragg's $\mathbf{k}_{\Gamma}(000)$ point, i.e. in the vicinity of a centre of the $1^{\text {st }} B Z$, although, the suggested models are valid for such a reciprocal-space region as well. Due to the special importance of mentioned information for quantitative interpretation of X-ray or thermal-neutron small-angle scattering data, such an analysis will be done exhaustively and separately in the forthcoming publication.

\section{STATISTICAL-THERMODYNAMICS MODEL OF THE SUBSTITUTIONAL ATOMIC SHORT-RANGE ORDER AND KINEMATICS OF THE DIFFUSE SCATTERING OF RADIATIONS IN F.C.C.-Ni-Fe-TYPE ALLOYS}

Within the scope of the SCF approximation [1-7] (at temperature, $T$, higher than the (Kurnakov) order-disorder phase transformation point, $T_{K}$ ), the equilibrium relation between the diffuse scattering in- 
tensities and the 'mixing' energies' Fourier components for a binary substitutional alloy is defined by the famous Krivoglaz-Clapp-Moss formula [10-13] as follows:

$$
I_{\mathrm{SRO}}(\mathbf{k}) \propto \tilde{\alpha}(\mathbf{k}) \cong \frac{D}{1+c(1-c) \beta \tilde{w}_{\text {tot }}(\mathbf{k})},
$$

where $\tilde{\alpha}(\mathbf{k})$ is the $\mathbf{k}$-th Fourier component of the SRO parameters (or so-called diffuse scattering intensity, $I_{\mathrm{SRO}}(\mathbf{k})$, in dimensionless units [Laue units]); $\beta=\left(k_{B} T\right)^{-1}$ is proportional to the inverse absolute temperature; $c$ is the relative concentration of an alloying element; $k_{B}$ is the Boltzmann constant; $D$ is the normalization factor defined as [10-13]:

$$
\begin{aligned}
D & \cong\left[\frac{1}{\Omega} \int_{\mathbf{k} \in 1^{\mathrm{st}} B Z} d \mathbf{k} \tilde{\alpha}(\mathbf{k})\right]\left[\frac{1}{N_{\text {u.c. }}} \sum_{\mathbf{k} \in 1^{\mathrm{st}} B Z} \frac{1}{1+c(1-c) \beta \tilde{w}_{\text {tot }}(\mathbf{k})}\right]^{-1}= \\
& =\left[\frac{1}{N_{\text {u.c. }}} \sum_{\mathbf{k} \in 1^{\text {st }} B Z} \frac{1}{1+c(1-c) \beta \tilde{w}_{\text {tot }}(\mathbf{k})}\right]^{-1} .
\end{aligned}
$$

In Eq. (2), the integration is carried out over the volume $\Omega$ of the $1^{\text {st }} B Z$. Replacing the integral by the sum leads to the summation that should be carried over all the $N_{\text {u.c. }}$ points of quasi-continuum with quasi-wave vectors $\mathbf{k}$ belonging to the $1^{\text {st }} B Z$. Note that, for many alloys, the coefficient $D \approx 1$ with accuracy of about $3 \%$ (this statement is also true for f.c.c.$\mathrm{Ni}-\mathrm{Fe}$ alloy; for details, see analysis in Sec. 3). One should note that, in all theories and approximations [10-61], the factor $D$ is defined by Eq. (2) with distinctions only in the definition of the so-called total 'mixing'-energies' Fourier components of an alloy, $\tilde{w}_{\text {tot }}(\mathbf{k})$ (see below).

In Eqs (1) and (2), the total 'mixing'-energies' Fourier components, $\tilde{w}_{\text {tot }}(\mathbf{k})$, and the atomic SRO parameters' Fourier components, $\tilde{\alpha}(\mathbf{k})$ (i.e. diffuse scattering intensities, $I_{\mathrm{SRO}}(\mathbf{k})$ ), are defined by corresponding quantities in a direct space by means of the conventional Fourier transform as follow [1-9]:

$$
\tilde{w}_{\text {tot }}(\mathbf{k})=\sum_{\mathbf{r}=\mathbf{R}-\mathbf{R}^{\prime}} w_{\text {tot }}(\mathbf{r}) \exp (-i \mathbf{k} \cdot \mathbf{r}), \tilde{\alpha}(\mathbf{k})=\sum_{\mathbf{r}=\mathbf{R}-\mathbf{R}^{\prime}} \alpha(\mathbf{r}) \exp (-i \mathbf{k} \cdot \mathbf{r}),(3 \mathrm{a})
$$

where, taking into account the intrinsic self-consistency of Eqs (1) and (2), the following constraints should be satisfied [1-9]:

$$
\begin{gathered}
\left.\alpha(\mathbf{r}=\mathbf{0}) \equiv 1 \quad \text { (i.e. } \sum_{\mathbf{k} \in 1^{\mathrm{st}} B Z} \tilde{\alpha}(\mathbf{k}) \equiv N_{\text {u.c. }}\right), \\
\left.w_{\text {indirect }}(\mathbf{r}=\mathbf{0}) \equiv \mathbf{0} \quad \text { (i.e. } \sum_{\mathbf{k} \in 1^{\mathrm{st}} B Z} \tilde{w}_{\text {indirect }}(\mathbf{k}) \equiv \mathbf{0}\right) .
\end{gathered}
$$

In fact, the second formula in Eq. (3b) means the gauge condition of 
the lack of indirect self-action of atoms in alloys. Furthermore, in the second formula of Eq. (3a), the quantities $\alpha(\mathbf{r})$ define the so-called Warren-Cowley SRO parameters determined as follow [1-9]:

$$
\alpha(\mathbf{r})=1-P^{A B}(\mathbf{r}) /(1-c)=1-P^{B A}(\mathbf{r}) / c,
$$

where $1-c(c)$ is the average concentration of $A(B)$ kind atom, $P^{A B}(\mathbf{r})$ $\left(P^{B A}(\mathbf{r})\right)$ is the 'two-particle' probability of finding of $A(B)$ kind atom separated by a distance $\mathbf{r}=\mathbf{R}-\mathbf{R}^{\prime}$ from $B(A)$ kind atom located at the origin $(\mathbf{r}=\mathbf{0})$ in a substitutional solid solution $A_{1-c} B_{c}$ based on the Bravais lattice.

In Eq. (3a), $w_{\text {tot }}(\mathbf{r})$ is the total 'mixing' energy presented in terms of a certain coordination shell with a radius-vector $\mathbf{r}$ and defined through the 'pairwise' interatomic 'mixing' energies as follows [1-9]:

$$
w_{\text {tot }}(\mathbf{r})=W_{\text {tot }}^{A A}(\mathbf{r})+W_{\text {tot }}^{B B}(\mathbf{r})-2 W_{\text {tot }}^{A B}(\mathbf{r}),
$$

where $W_{\mathrm{tot}}^{\alpha \beta}(\mathbf{r})$ are the energies of a total 'pairwise' interaction between the atoms $(\alpha, \beta=A, B)$ located at the sites $\mathbf{R}$ and $\mathbf{R}^{\prime}$ at the distance $\mathbf{r}$ from each other. As it was shown in [56-61], the total 'mixing' energy for f.c.c.-Ni-Fe alloys can be presented as a sum of three microscopic energy contributions, namely, 'direct' short-range interaction, e.g., (i) 'electrochemical' or (ii) magnetic (for instance, Ising- or Heisenbergtype 'exchange') interactions, and (iii) indirect interaction, i.e. 'straininduced' one (which is long-range and quasi-oscillating in a real space). Note that the 'electrochemical' interactions are usually referred to as the 'atom-atom' or 'ion-ion' 'effective' interactions arising between the atoms (ions) located at the sites of a rigid (non-relaxed) crystal lattice. This interaction has an electromagnetic nature matched with exchange-correlation effects. The 'strain-induced' interaction arises because of interference of the local static distortion fields of a host crystal lattice due to introduction of alloying atoms. In other words, this contribution takes into account semi-phenomenologically the atomic-sizes' mismatch effects in an alloy. An exhaustive theoretical analysis of all these 'mixing' energy contributions for f.c.c.-Ni-Fe alloys and most salient literature in this matter can be found elsewhere [59,60].

By the analogy with Refs [10-55], but based on the SCF and MSCF approximations [56-61], one can immediately develop the simple model for calculation of the kinematic diffuse-scattering intensity for substitutional (para)magnetic f.c.c.-Ni-Fe alloys with two magnetic constituents. Thus, in general case, such a part of the scattered-radiation intensity is caused by both the composition and magnetic-moments' fluctuations in an alloy. Along with the rigorous model, the simple interpolating approach can also be suggested. Thus, according to Eqs (1) and (2), one should calculate the total 'mixing' energies' Fourier component, $\tilde{w}_{\text {tot }}(\mathbf{k})$, as a function of temperature, $T$, and composition, $c$.

Let us consider briefly the statistical-thermodynamics model of 
such an alloy. As shown in [56-61], the total configuration-dependent part of free energy of (dis)ordered f.c.c.-Ni-Fe alloy is as follows: $F_{\text {conf }}^{\text {tot }}=U_{\text {conf }}^{\text {at }}+U_{\text {conf }}^{\text {mag }}-T\left\{S_{\text {conf }}^{\text {at }}+\Sigma_{\alpha} S_{\text {conf }}^{\text {mag }(\alpha)}\right\}$, where $U_{\text {conf }}$ and $S_{\text {conf }}$ are the configuration internal energies and entropy, respectively, for both atomic (at) and magnetic (mag) interacting subsystems of an alloy $(\alpha=\mathrm{Ni}, \mathrm{Fe})$. According to [56-61], the configuration entropy of the magnetic subsystem (i.e. moments with the spin numbers $s_{\alpha}=1 / 2,1$, $3 / 2,2$ or $5 / 2, \ldots)$ in the long-range ordered magnetic states such as the ferromagnetic or ferrimagnetic ones can be presented within the scope of the correlationless (MSCF) approximation as follows [56-65]:

$$
S_{\text {conf }}^{\mathrm{mag}(\alpha)} \cong N_{\text {u.c. }} k_{B} c_{\alpha}\left\{\ln \operatorname{sh}\left[\left(1+\frac{1}{2 s_{\alpha}}\right) y_{\alpha}\right]-\ln \operatorname{sh}\left[\frac{1}{2 s_{\alpha}} y_{\alpha}\right]-y_{\alpha} B_{s_{\alpha}}\left(y_{\alpha}\right)\right\} \text {. }
$$

Here, $B_{s_{\alpha}}\left(y_{\alpha}\right)$ is the conventional Brillouin function defined as [62-64]:

$$
B_{s_{\alpha}}\left(y_{\alpha}\right)=\left(1+\frac{1}{2 s_{\alpha}}\right) \operatorname{cth}\left[\left(1+\frac{1}{2 s_{\alpha}}\right) y_{\alpha}\right]-\frac{1}{2 s_{\alpha}} \operatorname{cth}\left[\frac{1}{2 s_{\alpha}} y_{\alpha}\right],
$$

$y_{\alpha} \equiv\left(s_{\alpha} H_{\text {eff }}^{\alpha}\right) /\left(k_{B} T\right)$ is the magnetic-to-thermal-energy ratio corresponding to the Weiss intracrystalline 'molecular' field $H_{\text {eff }}^{\alpha} \cong-g \mu_{B} \sum_{\beta} \Gamma_{\alpha \beta} \sigma_{\beta}$ (within the MSCF approximation with coefficients $\left.\left\{\Gamma_{\alpha \beta}\right\}\right), \sigma_{\alpha}$ is the specific spontaneous magnetization of $\alpha$-th magnetic subsystem $(\alpha=\mathrm{Ni}$, $\mathrm{Fe}), g$ is the Landé factor, $\mu_{B}$ is the Bohr magneton.

The configuration entropy for atomic subsystem of a binary alloy within the $(T-c)$-domain of disordered state (with SRO only) can be presented in the correlationless 'regular solid solution' form [1-7]:

$$
S_{\text {conf }}^{\text {at }} \cong-N_{\text {u.c. }} k_{B}[c \ln c+(1-c) \ln (1-c)] .
$$

Within the scope of the correlationless approximation, configuration internal energies of magnetic and atomic interacting subsystems in the atomic SRO state of f.c.c.-Ni-Fe alloy have the forms as follow [56-61]:

$$
\begin{aligned}
U_{\mathrm{conf}}^{\mathrm{mag}} \cong & \frac{1}{2} N_{\text {u.c. }}\left[\tilde{J}_{\mathrm{FeFe}}(0) c^{2} \sigma_{\mathrm{Fe}}^{2} s_{\mathrm{Fe}}^{2}+\tilde{J}_{\mathrm{NiNi}}(0)(1-c)^{2} \sigma_{\mathrm{Ni}}^{2} s_{\mathrm{Ni}}^{2}+\right. \\
+ & \left.2 \tilde{J}_{\mathrm{FeNi}}(0) c(1-c) \sigma_{\mathrm{Fe}} \sigma_{\mathrm{Ni}} s_{\mathrm{Fe}} s_{\mathrm{Ni}}\right] \\
& \quad U_{\mathrm{conf}}^{\mathrm{at}} \cong \Delta U_{0 \mathrm{prm}}+\frac{1}{2} N_{\text {u.c. }} \tilde{w}_{\mathrm{prm}}(0) c^{2}
\end{aligned}
$$

respectively. In Eq. (8), $\tilde{J}_{\alpha \alpha^{\prime}}(\mathbf{0})$ is the 'exchange'-integrals' Fourier component ( $\alpha, \alpha^{\prime}=\mathrm{Ni}, \mathrm{Fe}$ ) corresponding to $\mathbf{k}=\mathbf{0}$. In Eq. (9), $\Delta U_{0 \mathrm{prm}}$ is the configuration-dependent part of the internal energy, which is a linear function of the relative substitutional-atoms' concentration, $c$ ( $\mathrm{Fe}$ in 
f.c.c. $\mathrm{Ni}$ or $\mathrm{Ni}$ in f.c.c. $\mathrm{Fe})$; $\tilde{w}_{\text {prm }}(\mathbf{0})$ is the 'paramagnetic' 'mixing'energies' Fourier component within the $(T-c)$-domain of a paramagnetic alloy (i.e. above the Curie temperatures, where the replacement $\tilde{w}_{\text {tot }}(\mathbf{k}) \rightarrow \tilde{w}_{\text {prm }}(\mathbf{k})$ is valid; for details, see below). Finally, considering the above-mentioned approximation of the total configuration-dependent part of free energy of an alloy, $F_{\text {conf }}^{\text {tot }}$, and taking into account Eqs (5)-(9), one can immediately obtain a relation, e.g., for (para)magnetic f.c.c. $-\mathrm{Ni}_{1-c} \mathrm{Fe}_{c}$ alloy with the atomic $\mathrm{SRO}$ only in the following form:

$$
\begin{aligned}
& \frac{F_{\text {conf }}^{\text {tot }}}{N_{\text {u.c. }}} \cong \frac{\Delta U_{0 \text { prm }}}{N_{\text {u.c. }}}+\frac{1}{2}\left[\tilde{w}_{\mathrm{prm}}(\mathbf{0}) c^{2}+\tilde{J}_{\mathrm{FeFe}}(\mathbf{0}) c^{2} \sigma_{\mathrm{Fe}}^{2} s_{\mathrm{Fe}}^{2}+\tilde{J}_{\mathrm{NiNi}}(\mathbf{0})(1-c)^{2} \sigma_{\mathrm{Ni}}^{2} s_{\mathrm{Ni}}^{2}+\right. \\
& \left.+2 \tilde{J}_{\mathrm{FeNi}}(\mathbf{0}) c(1-c) \sigma_{\mathrm{Fe}} \sigma_{\mathrm{Ni}} s_{\mathrm{Fe}} s_{\mathrm{Ni}}\right]+k_{\mathrm{B}} T[c \ln c+(1-c) \ln (1-c)]- \\
& -k_{\mathrm{B}} T\left\{c\left[\ln \operatorname{sh}\left[\left(1+\frac{1}{2 s_{\mathrm{Fe}}}\right) y_{\mathrm{Fe}}\left(\sigma_{\mathrm{Fe}}\right)\right]-\ln \operatorname{sh}\left(\frac{1}{2 s_{\mathrm{Fe}}} y_{\mathrm{Fe}}\left(\sigma_{\mathrm{Fe}}\right)\right)-\sigma_{\mathrm{Fe}} y_{\mathrm{Fe}}\left(\sigma_{\mathrm{Fe}}\right)\right]+\right. \\
& \left.+(1-c)\left[\ln \operatorname{sh}\left[\left(1+\frac{1}{2 s_{\mathrm{Ni}}}\right) y_{\mathrm{Ni}}\left(\sigma_{\mathrm{Ni}}\right)\right]-\ln \operatorname{sh}\left(\frac{1}{2 s_{\mathrm{Ni}}} y_{\mathrm{Ni}}\left(\sigma_{\mathrm{Ni}}\right)\right)-\sigma_{\mathrm{Ni}} y_{\mathrm{Ni}}\left(\sigma_{\mathrm{Ni}}\right)\right]\right\} .
\end{aligned}
$$

Based on Eq. (10), one can see that $F_{\text {conf }}^{\text {tot }}$ can be transformed immediately into its classical form [1-7] within the $(T-c)$-domain of a paramagnetic alloy (i.e. above the Curie temperatures, where the replacement $F_{\text {conf }}^{\text {tot }} \rightarrow F_{\text {conf }}^{\text {prm }}$ is valid too). Using Eq. (10) and considering conditions when the derivatives of free energy, $\partial F_{\text {conf }}^{\text {tot }} / \partial \sigma_{\mathrm{Fe}}$ and $\partial F_{\text {conf }}^{\text {tot }} / \partial \sigma_{\mathrm{Ni}}$, are equal to 0 for thermodynamically equilibrium state, the set of transcendental equations is obtained for determination of the specific spontaneous magnetizations, $\sigma_{\mathrm{Fe}}$ and $\sigma_{\mathrm{Ni}}$, of both magnetic subsystems:

$$
\begin{gathered}
\sigma_{\mathrm{Ni}} \cong B_{s_{\mathrm{Ni}}}\left(-\frac{1}{(1-c) k_{B} T}\left\{\tilde{J}_{\mathrm{NiNi}}(\mathbf{0})(1-c)^{2} s_{\mathrm{Ni}}^{2} \sigma_{\mathrm{Ni}}+\tilde{J}_{\mathrm{FeNi}}(\mathbf{0}) c(1-c) s_{\mathrm{Fe}} s_{\mathrm{Ni}} \sigma_{\mathrm{Fe}}\right\}\right), \\
\sigma_{\mathrm{Fe}} \cong B_{s_{\mathrm{Fe}}}\left(-\frac{1}{c k_{B} T}\left\{\tilde{J}_{\mathrm{FeFe}}(\mathbf{0}) c^{2} s_{\mathrm{Fe}}^{2} \sigma_{\mathrm{Fe}}+\tilde{J}_{\mathrm{FeNi}}(\mathbf{0}) c(1-c) s_{\mathrm{Fe}} s_{\mathrm{Ni}} \sigma_{\mathrm{Ni}}\right\}\right) .
\end{gathered}
$$

In Eq. (10), the specific combination of $\tilde{w}_{\text {prm }}(\mathbf{0})$ and $\tilde{J}_{\alpha \alpha^{\prime}}(\mathbf{0})$ gives the so-called total 'mixing' energies' Fourier component of an alloy for 'fundamental' Bragg's $\Gamma(000)$ point, and thus, for any quasi-wave vector within the $1^{\text {st }} B Z$, it can be presented as follows [56-61]:

$$
\begin{aligned}
& \tilde{w}_{\mathrm{tot}}(\mathbf{k}) \approx \tilde{w}_{\mathrm{prm}}(\mathbf{k})+\tilde{w}_{\mathrm{mag}}(\mathbf{k}) \cong \tilde{\varphi}_{\mathrm{chem}}(\mathbf{k})+\tilde{V}_{\mathrm{si}}^{\mathrm{FeFe}}(\mathbf{k})+\tilde{w}_{\mathrm{mag}}(\mathbf{k}) \cong \tilde{\varphi}_{\mathrm{chem}}(\mathbf{k})+ \\
& +\tilde{V}_{\mathrm{si}}^{\mathrm{FeFe}}(\mathbf{k})+\tilde{J}_{\mathrm{NiNi}}(\mathbf{k}) \sigma_{\mathrm{Ni}}^{2} s_{\mathrm{Ni}}^{2}+\tilde{J}_{\mathrm{FeFe}}(\mathbf{k}) \sigma_{\mathrm{Fe}}^{2} s_{\mathrm{Fe}}^{2}-2 \tilde{J}_{\mathrm{NiFe}}(\mathbf{k}) \sigma_{\mathrm{Ni}} \sigma_{\mathrm{Fe}} s_{\mathrm{Ni}} s_{\mathrm{Fe}} \cdot
\end{aligned}
$$


In Eq. (12), $\tilde{\varphi}_{\text {chem }}(\mathbf{k})$ and $\tilde{V}_{\text {si }}^{\alpha \alpha}(\mathbf{k})$ are the Fourier components of 'electrochemical' 'mixing' energies and substitutional-atoms' $(\alpha-\alpha)$ 'straininduced' interaction energies, respectively. As a result, from (12), one can see that the total 'mixing' energies' Fourier components are the temperature and concentration dependent quantities (due to the contributions of $\tilde{w}_{\text {prm }}(\mathbf{k}, c, T)$ and $\tilde{w}_{\text {mag }}(\mathbf{k}, c, T)$; for details, see an analysis in [60]) and uniquely determine the diffuse-scattering intensities of radiations, $I_{\mathrm{SRO}}(\mathbf{k}, c, T)(1)$, for magnetic binary substitutional alloys at presence of composition-magnetic moments' fluctuations. Thus, omitting the 'weak' temperature dependence of 'paramagnetic' 'mixing' energies, $\tilde{w}_{\text {prm }}(\mathbf{k}, c, T)$ [60], the pronounced temperature dependence of $\tilde{w}_{\text {tot }}(\mathbf{k}, c, T)(12)$ at constant composition arises mostly due to the temperature dependences of spontaneous magnetizations for both magnetic subsystems, $\sigma_{\mathrm{Fe}}(c, T)$ and $\sigma_{\mathrm{Ni}}(c, T)$, explicitly defined by Eq. (11). Note that, within the paramagnetic domain of a magnetic-alloy phase diagram, Eq. (12) corresponds immediately to the classical KCMapproximation constraint with the $(T-c)$-independent value of $\tilde{w}_{\text {tot }}(\mathbf{k})$.

In order to express the total 'mixing' energies in the explicit form as a function of temperature, one can consider a simplest interpolation model for approximate estimation. Thus, according to [65] (see also a set of quite similar representations in [62-64]), the temperature dependence of the spontaneous magnetization in Eqs (11) for $\alpha$-th $(\alpha=\mathrm{Ni}, \mathrm{Fe})$ subsystem of atomically disordered alloys based on a cubic Bravais lattice at certain composition can be presented by the approximate relation:

$$
\sigma_{\alpha} \cong\left(1+\kappa_{\alpha} \frac{T}{T_{C}}\right) \sqrt{1-\frac{T}{T_{C}}} .
$$

Here, $\kappa_{\alpha}$ is the adjustable parameter, which depends on a concentration. Substituting Eq. (13) into (12), we obtain immediately as follows:

$$
\tilde{w}_{\text {tot }}(\mathbf{k}) \cong a_{0}(\mathbf{k})+a_{1}(\mathbf{k}) T+a_{2}(\mathbf{k}) T^{2}+a_{3}(\mathbf{k}) T^{3} .
$$

One can easily find that the wave-vector-dependent coefficients, $a_{0}(\mathbf{k})$, $a_{1}(\mathbf{k}), a_{2}(\mathbf{k}), a_{3}(\mathbf{k})$, entered into Eq. (14), are defined as follow:

$$
\begin{aligned}
a_{0}(\mathbf{k})= & \tilde{\varphi}_{\mathrm{chem}}(\mathbf{k})+\tilde{V}_{\mathrm{si}}^{\mathrm{FeFe}}(\mathbf{k})+\tilde{J}_{\mathrm{FeFe}}(\mathbf{k}) s_{\mathrm{Fe}}^{2}+\tilde{J}_{\mathrm{NiNi}}(\mathbf{k}) s_{\mathrm{Ni}}^{2}-2 \tilde{J}_{\mathrm{NiFe}}(\mathbf{k}) s_{\mathrm{Ni}} s_{\mathrm{Fe}}, \\
a_{1}(\mathbf{k})= & T_{C}^{-1}\left[\tilde{J}_{\mathrm{FeFe}}(\mathbf{k}) s_{\mathrm{Fe}}^{2}\left(2 \kappa_{\mathrm{Fe}}-1\right)+\tilde{J}_{\mathrm{NiNi}}(\mathbf{k}) s_{\mathrm{Ni}}^{2}\left(2 \kappa_{\mathrm{Ni}}-1\right)-\right. \\
& \left.-2 \tilde{J}_{\mathrm{NiFe}}(\mathbf{k}) s_{\mathrm{Ni}} s_{\mathrm{Fe}}\left(\kappa_{\mathrm{Ni}}+\kappa_{\mathrm{Fe}}-1\right)\right], \\
a_{2}(\mathbf{k})= & T_{C}^{-2}\left[\tilde{J}_{\mathrm{FeFe}}(\mathbf{k}) s_{\mathrm{Fe}}^{2}\left(\kappa_{\mathrm{Fe}}^{2}-2 \kappa_{\mathrm{Fe}}\right)+\tilde{J}_{\mathrm{NiNi}}(\mathbf{k}) s_{\mathrm{Ni}}^{2}\left(\kappa_{\mathrm{Ni}}^{2}-2 \kappa_{\mathrm{Ni}}\right)-\right. \\
& \left.-2 \tilde{J}_{\mathrm{NiFe}}(\mathbf{k}) s_{\mathrm{Ni}} s_{\mathrm{Fe}}\left(\kappa_{\mathrm{Ni}} \kappa_{\mathrm{Fe}}-\kappa_{\mathrm{Ni}}-\kappa_{\mathrm{Fe}}\right)\right], \\
a_{3}(\mathbf{k})= & -T_{C}^{-3}\left[\tilde{J}_{\mathrm{FeFe}}(\mathbf{k}) s_{\mathrm{Fe}}^{2} \kappa_{\mathrm{Fe}}^{2}+\tilde{J}_{\mathrm{NiNi}}(\mathbf{k}) s_{\mathrm{Ni}}^{2} \kappa_{\mathrm{Ni}}^{2}-2 \tilde{J}_{\mathrm{NiFe}}(\mathbf{k}) s_{\mathrm{Ni}} s_{\mathrm{Fe}} \kappa_{\mathrm{Ni}} \kappa_{\mathrm{Fe}}\right] .
\end{aligned}
$$


Next, within the scope of the MSCF approximation, the magnetic phase-transition temperature (Curie temperature), $T_{C}$, entered into Eq. (15), is determined by the 'exchange' 'integrals' of magnetic interactions, $\tilde{J}_{\alpha \prime^{\prime}}(\mathbf{0})$, and the concentration of Fe atoms, $c$, in a homogeneous atomic SRO state exclusively in accordance with the formula [56-60]:

$$
\begin{aligned}
T_{C} \cong & -\left(6 k_{\mathrm{B}}\right)^{-1}\left\{\left(1+s_{\mathrm{Ni}}\right) s_{\mathrm{Ni}} \tilde{J}_{\mathrm{NiNi}}(0)(1-c)+\left(1+s_{\mathrm{Fe}}\right) s_{\mathrm{Fe}} \tilde{J}_{\mathrm{FeFe}}(0) c-\right. \\
& -\left[\left(\left(1+s_{\mathrm{Ni}}\right) s_{\mathrm{Ni}} \tilde{J}_{\mathrm{NiNi}}(0)(1-c)-\left(1+s_{\mathrm{Fe}}\right) s_{\mathrm{Fe}} \tilde{J}_{\mathrm{FeFe}}(0) c\right)^{2}+\right. \\
& \left.\left.+4\left(1+s_{\mathrm{Ni}}\right) s_{\mathrm{Ni}}\left(1+s_{\mathrm{Fe}}\right) s_{\mathrm{Fe}} \tilde{J}_{\mathrm{NiFe}}^{2}(0) c(1-c)\right]^{1 / 2}\right\} .
\end{aligned}
$$

Thereby, combining of Eqs (14), (15) and (16), we arrive at the same conclusion as in the case of above-mentioned SCF + MSCF model, namely, that, in the magnetic $(T-c)$-domain of an alloy, the total 'mixing' energies' Fourier components are the $(T-c)$-dependent quantities. Moreover, as can be seen from Eq. (14), such dependences at constant composition can be approximated by the polynomial temperature dependences of the $3^{\text {rd }}$ order, where the parameters, $a_{0}(\mathbf{k}), a_{1}(\mathbf{k}), a_{2}(\mathbf{k})$, $a_{3}(\mathbf{k})$, in accordance with Eq. (15), are defined through the microscopic energy contributions of different natures. Finally, within the scope of both 'mixing' energies' Fourier components' representations for $\tilde{w}_{\text {tot }}(\mathbf{k})$ (i.e. in accordance with Eqs (12) and (14)), the diffuse scattering intensity of radiations, $I(\mathbf{k}) \propto \alpha(\mathbf{k})$, is still determined by the KCM formula (1) with an appropriate definition of the normalization factor $D(2)$.

\section{RESULTS AND DISCUSSION}

\subsection{Monte Carlo Simulations of the Atomic SRO States in (Para)Magnetic F.C.C.-Ni-Fe Alloys}

In order to model the local atomic configurations and corresponding diffuse scattering intensity patterns for f.c.c.-Ni-Fe alloys, the statistical MC simulation method [66-68] is used. The method is based on the most suitable MC algorithms, which have been developed before, with regard to the SRO modelling for binary substitutional alloys, and more details about these techniques can be found elsewhere [69-78]. Thus, the used algorithm is as follows: (i) the initial random configuration of $\mathrm{Ni}$ and $\mathrm{Fe}$ atoms (with respective concentrations, $c_{\mathrm{Ni}}=1-c$ and $c_{\mathrm{Fe}}=c ; c_{\mathrm{Ni}}+c_{\mathrm{Fe}}=1$ ) is generated over the sites of f.c.c. crystallite lattice with a linear size of $L=100$ unit-cell parameters (the total number of sites within the crystallite corresponds to $100 \times 100 \times 100 \times 4$ positions); (ii) two different $\mathrm{Ni}$ and/or Fe atoms are chosen randomly and ex- 
changed; (iii) the residual parameter $R$ is calculated in accordance with the following formula:

$$
R=\sum_{l m n}\left(\alpha_{l m n}^{\text {model }}-\alpha_{l m n}^{\exp }\right)^{2} / \sum_{l m n}\left(\alpha_{l m n}^{\exp }\right)^{2},
$$

where $\alpha_{l m n}^{\text {model }}, \alpha_{l m n}^{\exp }$ are the Warren-Cowley SRO parameters for modelled crystallite and experimental data, respectively; (iv) if the parameter $R$ decreases, the atoms are left at the 'new' positions, and otherwise, the exchange is rejected, the atoms are returned to the 'old' lattice sites. The steps (ii)-(iv) are repeated until $R$ reaches some minimum value, e.g., $10^{-(3-6)}$. Within the described algorithm, the exchange of atoms is realized between arbitrary-distant $\mathrm{Ni}$ and $\mathrm{Fe}$ atoms. Furthermore, the modelled alloy is considered without site vacancies that is the reasonable assumption only for analysis of the equilibrium SRO states with or without a long-range order (LRO) of the atomic spatial distribution. The periodic free-surface boundary conditions are also applied.

The $2 D(001) *$-type diffuse scattering intensity patterns are calculated using the conventional Fourier transformation (3) for both sets of Warren-Cowley SRO parameters, namely, experimental and modelled ones, $\alpha_{l m n}^{\exp }$ and $\alpha_{l m n}^{\text {model }}$, respectively.

The MC simulations are carried out for Permalloy $\left({ }^{62} \mathrm{Ni}_{0.765} \mathrm{Fe}_{0.235}[79]\right.$ or $\left.\mathrm{Ni}_{0.775} \mathrm{Fe}_{0.225}[81,82]\right)$, Elinvar $\left(\mathrm{Ni}_{0.535} \mathrm{Fe}_{0.465}\right.$ [81]) and Invar $\left(\mathrm{Fe}_{0.698}{ }^{62} \mathrm{Ni}_{0.302}\right.$ [80] or $\mathrm{Fe}_{0.632} \mathrm{Ni}_{0.368}$ [83]) compositions of f.c.c.-Ni-Fe alloys isothermally annealed at temperatures above and below the $\mathrm{Cu}$ rie points, $T_{C}$.

In Tables 1 and 2, the experimental Warren-Cowley SRO parameters, $\alpha_{l m n}^{\exp }$, taken from [79-83], where both the thermal neutrons with the Borie-Sparks-Gragg separation technique $[79,80]$ and the anomalous X-ray scattering methods with the $3 \lambda$ separation technique [8183] were used, are presented along with the SRO parameters calculated for modelled crystallites, $\alpha_{l m n}^{\text {model }}$, at Permalloy, Elinvar and Invar compositions and given isothermal annealing temperatures, $T_{a}$.

Then, using data from Tables 1 and 2 and Fourier transform (3), we have calculated the $2 D$ diffuse-scattering intensity patterns in $(001) *_{\text {- }}$ type plane of a reciprocal space for f.c.c.- Ni-Fe alloys, $I_{\mathrm{SRo}}(\mathbf{k}, c, T)(\mathrm{Figs}$ 1 and 2). As can be seen, the $2 D$ isodiffuse intensity distributions, $I_{\mathrm{SRO}}(\mathbf{k}, c, T)$, depend significantly on the $(T-c)$-region, where f.c.c.-NiFe alloys with the atomic SRO are considered.

From Figs 1 and 2, one can see that, in spite of the insignificant difference between the absolute values of both experimental and modelled diffuse intensity distributions, the $2 D$ diffraction patterns for modelled crystallites in their reciprocal-space representation details are in overall decent agreement with the experimentally measured ones [79-83].

As can also be seen from Figs 1 and 2, the maximum of the diffuse scattering intensities is localized at the $X(100)$-type superstructural 
points, $\mathbf{k}_{X}$, of a reciprocal space (with the insignificant elongation in $\left(1 k_{y} 0\right)$-type directions, which is probably due to the interference of the 'itinerant' electron waves with the static concentration waves when $k_{F} \cong k_{X}$, where $k_{F}$ is the Fermi wave number) that shows the preferential formation of the homogeneous atomic SRO states locally ordered like to the $L 1_{2}$-type superstructure unit cells.

TABLE 1. The Warren-Cowley SRO parameters, $\alpha_{l m n}^{\exp }$ (left columns), extracted from the neutron elastic diffuse scattering experiments $[79,80]$ for single crystals of f.c.c.-Ni-Fe alloys with various compositions, $c$, and at different annealing temperatures, $T_{a}$, as well as the modelled SRO parameters, $\alpha_{l m n}^{\text {model }}$ (right columns). The superscript ${ }^{62}$, denotes an atom of ${ }^{62} \mathrm{Ni}$ isotope.

\begin{tabular}{|c|c|c|c|c|c|c|c|c|c|}
\hline \multirow{2}{*}{$\begin{array}{l}\vec{\nabla} \\
\vec{d} \\
\text { d } \\
\dot{0} \\
\dot{z}\end{array}$} & \multirow[b]{2}{*}{ है } & \multicolumn{8}{|c|}{$\alpha_{l m n}^{\exp } \mid \alpha_{l m n}^{\text {model }}$} \\
\hline & & \multicolumn{2}{|c|}{$\begin{array}{c}{ }^{62} \mathrm{Ni}_{0.765} \mathrm{Fe}_{0.235} \\
808 \mathrm{~K}[79]\end{array}$} & \multicolumn{2}{|c|}{$\begin{array}{c}{ }^{62} \mathrm{Ni}_{0.765} \mathrm{Fe}_{0.235} \\
873 \mathrm{~K}[79]\end{array}$} & \multicolumn{2}{|c|}{$\begin{array}{c}{ }^{62} \mathrm{Ni}_{0.765} \mathrm{Fe}_{0.235} \\
958 \mathrm{~K}[79]\end{array}$} & \multicolumn{2}{|c|}{$\begin{array}{c}\mathrm{Fe}_{0.698}{ }^{62} \mathrm{Ni}_{0.302} \\
743 \mathrm{~K}[80]\end{array}$} \\
\hline & 000 & 0.932 & 1 & 1.1 & 1 & 0.988 & 1 & 1.0214 & 1 \\
\hline 1 & 110 & -0.111 & -0.1305 & -0.0868 & $3-0.0957$ & -0.0946 & -0.1310 & -0.0201 & -0.0282 \\
\hline 2 & 200 & 0.136 & 0.1388 & 0.100 & 0.1123 & 0.0848 & 0.0933 & 0.0451 & 0.0562 \\
\hline 3 & 211 & -0.006 & -0.0361 & -0.0024 & -0.0135 & -0.00302 & -0.0193 & 0.0046 & 0.0017 \\
\hline 4 & 220 & 0.052 & 0.0685 & 0.0200 & 0.0427 & 0.0183 & 0.0259 & 0.0042 & 0.0148 \\
\hline 5 & 310 & -0.022 & -0.0452 & 0.0140 & -0.0029 & -0.00823 & -0.0363 & 0.0003 & -0.0030 \\
\hline 6 & 222 & 0.031 & 0.0260 & 0.0175 & 0.0168 & 0.0067 & 0.0057 & 0.0042 & 0.0021 \\
\hline 7 & 321 & -0.014 & -0.0113 & -0.0026 & 0.0078 & -0.00205 & -0.0085 & 0.0008 & 0.0077 \\
\hline 8 & 400 & 0.022 & -0.0029 & 0.0084 & 0.0091 & 0.00612 & -0.0165 & 0.0037 & 0.0034 \\
\hline $9 a$ & 330 & -0.013 & -0.0376 & - & - & -0.00073 & -0.0192 & - & - \\
\hline $9 b$ & 411 & -0.013 & -0.0177 & - & - & -0.0034 & -0.0133 & - & - \\
\hline 10 & 420 & 0.001 & 0.0199 & - & - & 0.00392 & 0.0049 & - & - \\
\hline 11 & 332 & 0.019 & -0.0090 & - & - & -0.00093 & -0.0087 & - & - \\
\hline 12 & 422 & 0.005 & 0.0192 & - & - & 0.0041 & 0.0104 & - & - \\
\hline $13 a$ & 431 & 0.016 & -0.0009 & - & - & -0.0013 & -0.0043 & - & - \\
\hline $13 b$ & 510 & 0.016 & -0.0192 & - & - & -0.00032 & -0.0236 & - & - \\
\hline 14 & 521 & & 0.0039 & - & - & 0.000785 & 0.0057 & - & - \\
\hline 15 & 440 & -0.007 & -0.0167 & - & - & 0.00162 & -0.0131 & - & - \\
\hline $16 a$ & 433 & -0.007 & -0.0112 & - & - & -0.00059 & -0.0103 & - & - \\
\hline $16 b$ & 530 & -0.007 & -0.0098 & - & - & -0.0025 & -0.0098 & - & - \\
\hline $17 a$ & 442 & 0.008 & 0.0134 & - & - & 0.00121 & 0.0089 & - & - \\
\hline $17 b$ & 600 & 0.008 & -0.0374 & - & - & 0.000418 & -0.0348 & - & - \\
\hline $18 a$ & 532 & -0.008 & -0.0206 & - & - & -0.00105 & -0.0186 & - & - \\
\hline $18 b$ & 611 & -0.008 & 0.0026 & - & - & -0.00461 & 0.0027 & - & - \\
\hline 19 & 620 & -0.011 & 0.0055 & - & - & 0.00346 & 0.0018 & - & - \\
\hline 20 & 541 & 0.002 & 0.0027 & - & - & 0.000276 & -0.0016 & - & - \\
\hline 21 & 622 & 0.012 & 0.0097 & - & - & 0.00151 & 0.0063 & - & - \\
\hline 22 & 631 & 0.006 & -0.0002 & - & - & -0.00202 & -0.0032 & - & - \\
\hline 23 & 444 & - & -0.0144 & - & - & -0.00127 & -0.0124 & - & - \\
\hline
\end{tabular}


TABLE 2. The Warren-Cowley SRO parameters, $\alpha_{l m n}^{\exp }$ (left columns), extracted from the X-ray anomalous diffuse scattering experiments [81-83] for single crystals of f.c.c. $-\mathrm{Ni}_{1-c} \mathrm{Fe}_{c}$ alloys at different annealing temperatures, $T_{a}$, as well as the modelled SRO parameters, $\alpha_{l m n}^{\text {model }}$ (right columns).

\begin{tabular}{|c|c|c|c|c|c|c|c|}
\hline \multirow{2}{*}{$\begin{array}{l}\vec{\Xi} \\
\stackrel{\Xi}{0} \\
\dot{0} \\
\text { Z }\end{array}$} & \multirow{2}{*}{$\stackrel{\Xi}{\Xi}$} & \multicolumn{6}{|c|}{$\alpha_{l m n}^{\exp } \mid \alpha_{l m n}^{\text {model }}$} \\
\hline & & $\begin{array}{l}\mathrm{Ni}_{0.775} \mathrm{Fe}_{0.225} \\
1273 \mathrm{~K}[81]\end{array}$ & \multicolumn{2}{|c|}{$\begin{array}{l}\mathrm{Ni}_{0.775} \mathrm{Fe}_{0.225} \\
1273 \mathrm{~K}[82]\end{array}$} & $\begin{array}{l}\mathrm{Ni}_{0.535} \mathrm{Fe}_{0.465} \\
1273 \mathrm{~K}[81]\end{array}$ & \multicolumn{2}{|c|}{$\begin{array}{c}\mathrm{Fe}_{0.632} \mathrm{Ni}_{0.368} \\
753 \mathrm{~K}[83]\end{array}$} \\
\hline 0 & 000 & 1.00121 & 0.9901 & 1 & 1.00002 & 1.0025 & 1 \\
\hline 1 & 110 & $-0.10821-0.13664$ & -0.155 & $7-0.1518$ & $-0.07665-0.1396$ & -0.0583 & -0.0797 \\
\hline 2 & 200 & $\begin{array}{lll}0.11948 & 0.12729\end{array}$ & 0.1288 & 80.1363 & 0.064630 .10073 & 0.0522 & 0.0675 \\
\hline 3 & 211 & $-0.00472-0.02733$ & -0.016 & $5-0.0326$ & $-0.0022-0.0189$ & -0.0032 & -0.0107 \\
\hline 4 & 220 & $\begin{array}{lll}0.03077 & 0.05169\end{array}$ & 0.0217 & $\begin{array}{ll}7 & 0.0547\end{array}$ & $\begin{array}{lll}0.00371 & 0.01819\end{array}$ & 0.0002 & 0.0152 \\
\hline 5 & 310 & $-0.01792-0.05157$ & -0.022 & $4-0.0542$ & $-0.0100-0.0436$ & -0.0062 & -0.0186 \\
\hline 6 & 222 & $0.01305 \quad 0.00634$ & 0.0165 & 50.0087 & $0.00371-0.0084$ & - & - \\
\hline 7 & 321 & $-0.00752-0.01405$ & -0.012 & $3-0.0158$ & $-0.0039-0.0109$ & - & - \\
\hline 8 & 400 & $0.01734-0.00332$ & - & - & $0.00711-0.0028$ & - & - \\
\hline $9 a$ & 330 & $0.00052-0.03033$ & - & - & $-0.0022-0.0193$ & - & - \\
\hline $9 b$ & 411 & $0.00461-0.00766$ & - & - & $0.00077-0.0106$ & - & - \\
\hline 10 & 420 & $\begin{array}{ll}0.00483 & 0.01855\end{array}$ & - & - & 0.001280 .00355 & - & - \\
\hline 11 & 332 & $-0.00322-0.00897$ & - & - & $-0.00077-0.0090$ & - & - \\
\hline 12 & 422 & 0.003020 .01203 & - & - & -0.000370 .00 & - & - \\
\hline $13 a$ & 431 & $-0.00251-0.00426$ & - & - & $-0.00085-0.0054$ & - & - \\
\hline $13 b$ & 510 & $-0.00231-0.03124$ & - & - & $0.00026-0.0251$ & - & - \\
\hline 14 & 521 & $-0.00259-0.00172$ & - & - & $-0.00114-0.0001$ & - & - \\
\hline 15 & 440 & $0.002310-0.01563$ & - & - & $0.00077-0.0130$ & - & - \\
\hline $16 a$ & 433 & $-0.00422-0.01156$ & - & - & $0.00035-0.0066$ & - & - \\
\hline $16 b$ & 530 & $-0.00171-0.00793$ & - & - & $-0.00026-0.0073$ & - & - \\
\hline $17 a$ & 442 & 0.00199 & - & - & -0.0037 & - & - \\
\hline $17 b$ & 600 & $0.00873-0.03226$ & - & - & $-0.00379-0.0214$ & - & - \\
\hline
\end{tabular}

Moreover, by moving from Permalloy (of $\mathrm{L1}_{2}-\mathrm{Ni}_{3} \mathrm{Fe}$ type) through Elinvar (of $L 1_{0}-\mathrm{NiFe}$ type) to Invar (of $L 1_{2}-\mathrm{Fe}_{3} \mathrm{Ni}$ type) composition regions, the diffuse scattering intensities for the superstructural point $\mathbf{k}_{X}, I_{\mathrm{SRO}}\left(\mathbf{k}_{X}, c\right)$, decrease significantly. It can be explained by the significant decrease of values of the 'mixing' energies' Fourier components, $\tilde{w}_{\text {prm }}\left(\mathbf{k}_{X}, c\right)$, with increasing of Fe atoms' concentration (see Table 3 and Eqs (12) and (14) in line with [59,60]).

Using the Warren-Cowley SRO parameters of modelled crystallites, for instance, for f.c.c. ${ }^{62} \mathrm{Ni}_{0.765} \mathrm{Fe}_{0.235}$ Permalloy (Table 1) annealed at $T_{a}=958,873$ or $808 \mathrm{~K}$, the local atomic configurations of $\mathrm{Ni}$ and Fe atoms are reconstructed (Fig. 3). Due to the $L 1_{2(0)}$-type symmetry of LRO superstructures of f.c.c.-Ni-Fe alloys and for the ease of further analysis, the atomic distributions are presented in $(001) *$-type $2 D$ sections 

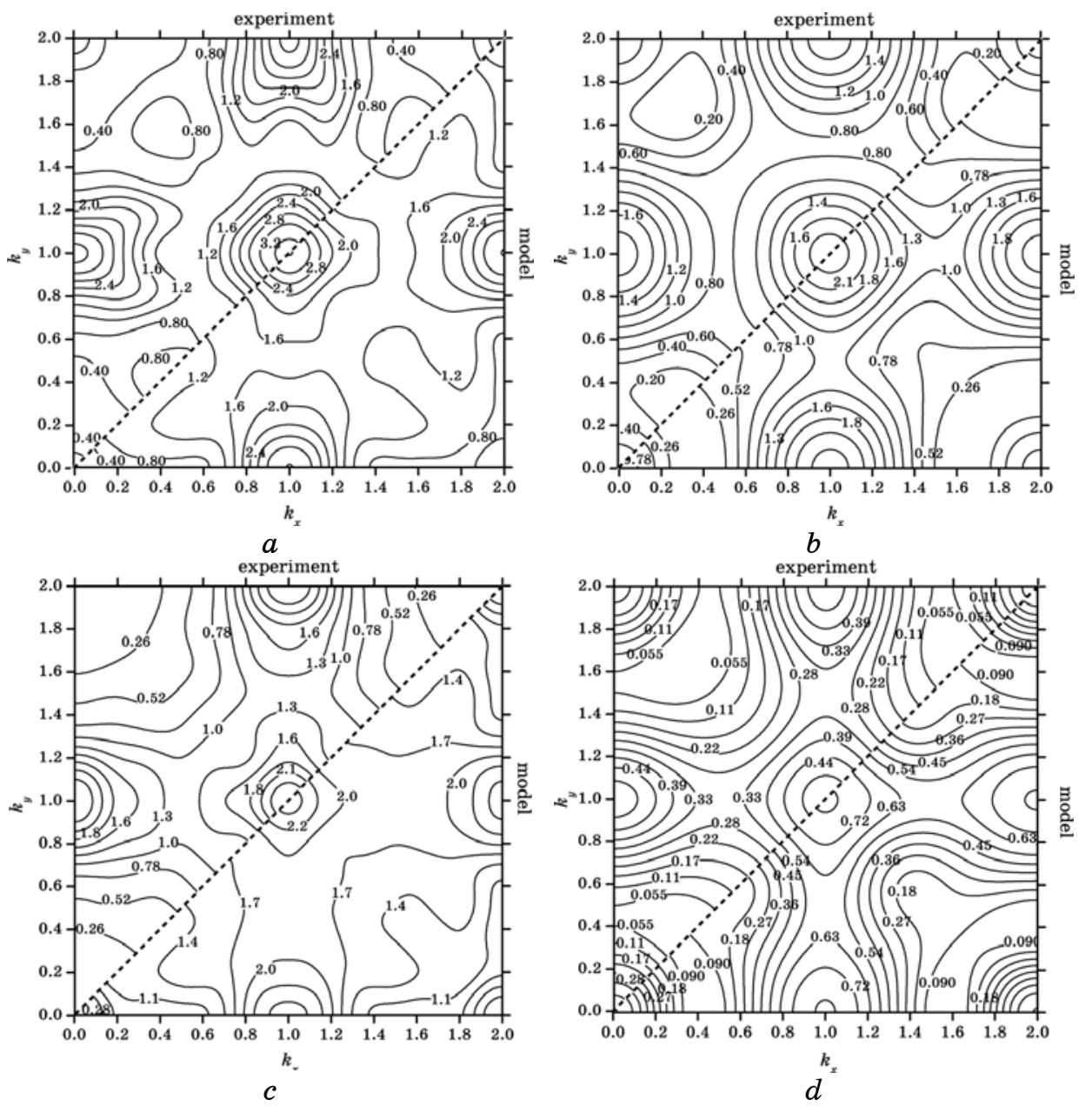

Fig. 1. The $2 D$ diffuse-scattering intensity patterns in $(001) *$-type plane of a reciprocal space, $I_{\mathrm{SRO}}(\mathbf{k}, c, T)$ in [Laue units]: $(a){ }^{62} \mathrm{Ni}_{0.765} \mathrm{Fe}_{0.235} @ 808 \mathrm{~K}$ [79], (b) ${ }^{62} \mathrm{Ni}_{0.765} \mathrm{Fe}_{0.235} @ 873 \mathrm{~K}$ [79], (c) ${ }^{62} \mathrm{Ni}_{0.765} \mathrm{Fe}_{0.235} @ 958 \mathrm{~K} \mathrm{[79],}(d) \mathrm{Fe}_{0.698}{ }^{62} \mathrm{Ni}_{0.302} @ 743$ $\mathrm{K}[80]$. The modelled data correspond to the MC simulation results.

in a direct space.

From Fig. 3, one can see that the number of LRO regions ordered by the $L 1_{2}$-type superstructure increases with decreasing temperature when changing from PMS (paramagnetic state of atomic SRO) region to FMS (ferromagnetic state of atomic SRO) one. As shown in [84], the diffuse scattering intensities significantly deviate from those predicted by the classical KCM formula (1) that confirms the conclusion made in [5661 ] about the essential role of the magnetic contribution into the total 'mixing' energies of an alloy within the FMS region (see analysis below). 

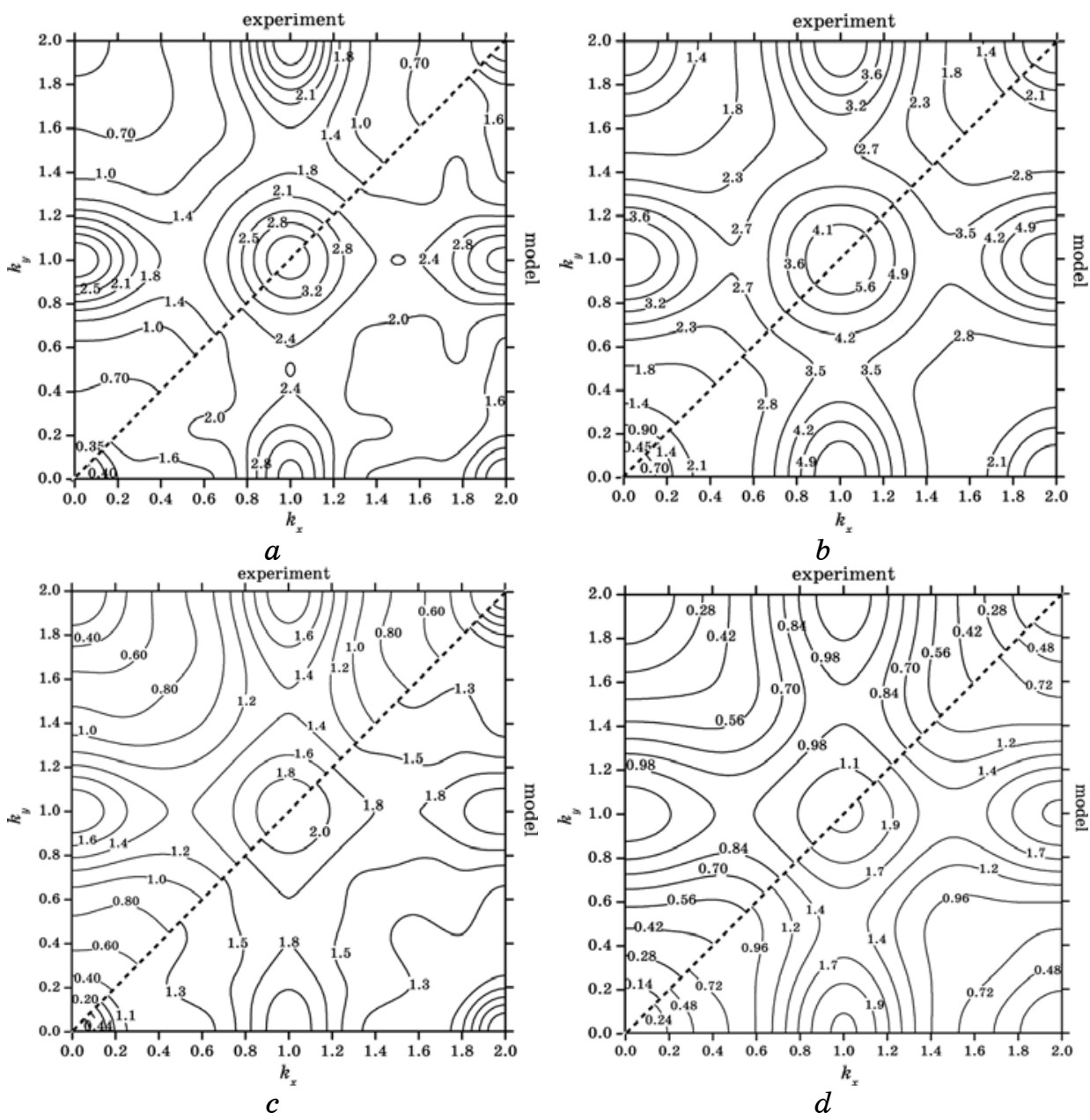

Fig. 2. The $2 D$ diffuse-scattering intensity patterns in (001)*-type plane of a reciprocal space, $I_{\mathrm{SRO}}(\mathbf{k}, c, T)$ in [Laue units]: $(a) \mathrm{Ni}_{0.775} \mathrm{Fe}_{0.225} @ 1273 \mathrm{~K}$ [81], $(b)$ $\mathrm{Ni}_{0.775} \mathrm{Fe}_{0.225} @ 1273 \mathrm{~K}$ [82], (c) $\mathrm{Ni}_{0.535} \mathrm{Fe}_{0.465} @ 1273 \mathrm{~K}$ [81], (d) $\mathrm{Fe}_{0.632} \mathrm{Ni}_{0.368} @ 753$ $\mathrm{K}$ [83]. The modelled data correspond to the MC simulation results.

\section{2. $(T-c)$-Dependence of the Atomic SRO States in (Para)Magnetic F.C.C.-Ni-Fe Alloys}

As shown recently in [60], the 'paramagnetic' 'mixing' energies Fourier components, $\tilde{w}_{\text {prm }}(\mathbf{k})$, calculated for quasi-wave vectors $\mathbf{k}$ along the high-symmetry $\Delta\left(\mathbf{k}_{\Gamma} \rightarrow \mathbf{k}_{X}\right)$ direction within the $1^{\text {st }} B Z$ are the concentration-dependent functions in accordance with the approximant:

$$
\tilde{w}_{\mathrm{prm}}(\mathbf{k}, c) \approx K_{0}(\mathbf{k})+K_{1}(\mathbf{k}) c+K_{2}(\mathbf{k}) c^{2}
$$




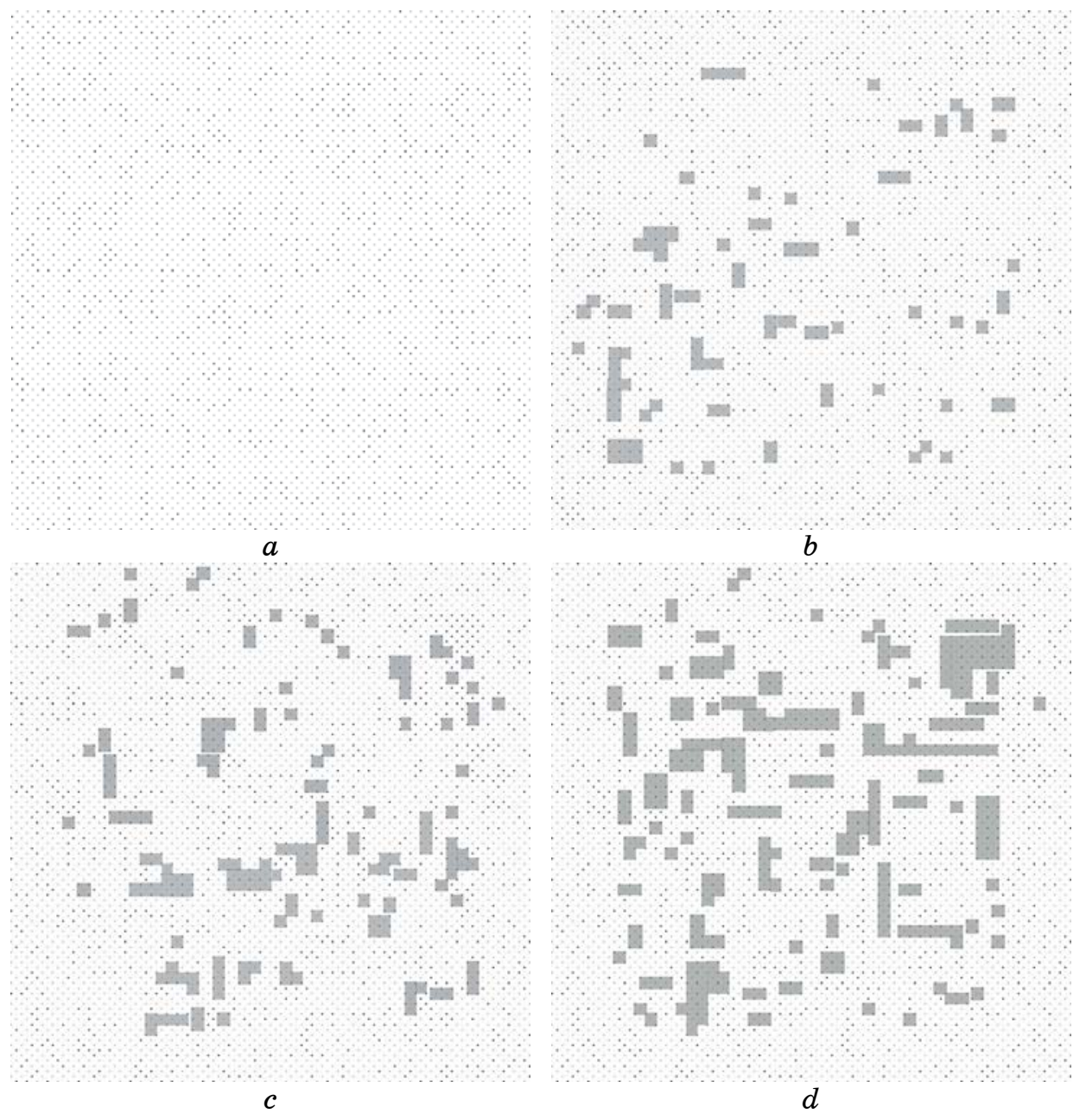

Fig. 3. The temperature dependence of $\mathrm{Ni}(\circ)$ and $\mathrm{Fe}(\bullet)$ atomic configurations in (001)*-type crystallographic plane for f.c.c. ${ }^{62} \mathrm{Ni}_{0.765} \mathrm{Fe}_{0.235}$ Permalloy obtained by the MC simulations: (a) initial random configuration; $(b),(c)$ and $(d)$ modelled atomic SRO configurations at $T_{a}=958,873$ and $808 \mathrm{~K}$, respectively. The chosen temperatures correspond to the respective annealing temperatures reported in [79]. The atomic $L 1_{2}-\mathrm{Ni}_{3} \mathrm{Fe}$ type LRO clusters are clearly visible and marked by dark areas.

with the fitting parameters, $K_{0}(\mathbf{k}), K_{1}(\mathbf{k})$ and $K_{2}(\mathbf{k})$, presented in Table 3 . The 'exchange' 'integrals' Fourier components for magnetic interactions, $\tilde{J}_{\alpha \alpha^{\prime}}(\mathbf{k})$, which were calculated within the scope of the MSCF approximation [58-60] for various possible spin numbers for $\mathrm{Ni}$ and $\mathrm{Fe}$ atoms in f.c.c.-Ni-Fe alloys, are presented in Table 4. As evidently from Table 4, the 'exchange' 'integrals' Fourier components, $\tilde{J}_{\mathrm{NiNi}}(\mathbf{k})$ and 
TABLE 3. The coefficients $K_{0}(\mathbf{k}), K_{1}(\mathbf{k})$ and $K_{2}(\mathbf{k})$ (in [eV]) entered into (18) for estimation of the concentration-dependent 'paramagnetic' 'mixing' energies Fourier components for quasi-wave vectors $\mathbf{k}$ within the $1^{\text {st }} B Z$, namely, $\mathbf{k}_{X}(100), \Delta\left(\mathbf{k}_{\Gamma} \rightarrow \mathbf{k}_{X}\right)$ and $\mathbf{k}_{\Gamma}(000)$, for f.c.c.- $\mathrm{Ni}_{1-c} \mathrm{Fe}_{c}$ alloys [60].

\begin{tabular}{c|c|c|c|c}
\hline $\mathbf{k}$ & $K_{0}(\mathbf{k})$ & $K_{1}(\mathbf{k})$ & $K_{2}(\mathbf{k})$ & Approximation \\
\hline$X\left(\begin{array}{lll}0 & 0 & 1\end{array}\right)$ & -0.414 & 0.450 & - & $1^{\text {st }}$ order \\
$X\left(\begin{array}{llll}0 & 0 & 1\end{array}\right) \rightarrow \Gamma\left(\begin{array}{lll}0 & 0 & 0\end{array}\right)$ & 0.855 & -2.177 & 2.087 & $2^{\text {nd }}$ order \\
$\Gamma\left(\begin{array}{llll}0 & 0 & 0\end{array}\right)$ & 0.843 & -2.339 & 2.344 & $2^{\text {nd }}$ order \\
\hline
\end{tabular}

TABLE 4. The 'exchange' (magnetic) interaction energies' Fourier components (in [meV]) for two quasi-wave vectors $\mathbf{k}$ within the $1^{\text {st }} B Z, \mathbf{k}_{X}(100)$ and $\mathbf{k}_{\Gamma}(000)$, depending on local spin numbers of $\mathrm{Ni}$ and $\mathrm{Fe}$ atoms in f.c.c.- $\mathrm{Ni}_{1-c} \mathrm{Fe}_{c}$ alloys $(c \in[0,1])[58-60]$.

\begin{tabular}{c|c|c|c|c|c|c|c}
\hline$s_{\mathrm{Ni}}$ & $s_{\mathrm{Fe}}$ & $\tilde{J}_{\mathrm{NiNi}}(\mathbf{0})$ & $\tilde{J}_{\mathrm{FeFe}}(\mathbf{0})$ & $\tilde{J}_{\mathrm{NiFe}}(\mathbf{0})$ & $\tilde{J}_{\mathrm{NiNi}}\left(\mathbf{k}_{X}\right)$ & $\tilde{J}_{\mathrm{FeFe}}\left(\mathbf{k}_{X}\right)$ & $\tilde{J}_{\mathrm{NiFe}}\left(\mathbf{k}_{X}\right)$ \\
\hline $1 / 2$ & $1 / 2$ & -215.9 & 274.6 & -517.6 & 72.0 & -91.5 & 172.5 \\
$1 / 2$ & 1 & -215.9 & 103.0 & -316.9 & 72.0 & -34.3 & 105.6 \\
$1 / 2$ & $3 / 2$ & -215.9 & 54.9 & -231.5 & 72.0 & -18.3 & 77.2 \\
\hline
\end{tabular}

$\tilde{J}_{\mathrm{NiFe}}(\mathbf{k})$, correspond to ferromagnetic interactions, and $\tilde{J}_{\mathrm{FeFe}}(\mathbf{k})$ corresponds to the antiferromagnetic character. In spite of the recently appeared and debatable point of view about the completely ferromagnetic interactions in f.c.c.-Ni-Fe alloys, our result is in an overall agreement with many experimental and theoretical findings (see Refs [56-60] and references therein) as well as with the conception of f.c.c. $\gamma$-Fe itself.

As shown by means of the MC simulations above, the atomic SRO states of f.c.c.- $\mathrm{Ni}-\mathrm{Fe}$ alloys depend significantly on the $(T-c)$-region where a certain solid solution is considered.

Using the concentration dependence of the 'paramagnetic' 'mixing' energies' Fourier components, $\tilde{w}_{\text {prm }}(\mathbf{k}, c)$, for two quasi-wave vectors $\mathbf{k}$ within the $1^{\text {st }} B Z, \mathbf{k}_{X}$ and $\mathbf{k}_{\Gamma}$, (Table 3 ) and the temperature-concentration dependence of the magnetic 'mixing' energies' Fourier components, $\tilde{w}_{\text {mag }}(\mathbf{k}, c, T)$ (according to (11) and (12)), one can calculate the $(T-c)$-dependences of the diffuse SRO intensity, $I_{\mathrm{SRo}}(\mathbf{k}, c, T)$, by means of the KCM formula (1). Here, all calculations are done for three cases: (i) $\tilde{w}_{\text {tot }}(\mathbf{k}) \equiv \tilde{w}_{\text {prm }}(\mathbf{k})=$ const [10-13], (ii) $\tilde{w}_{\text {tot }}(\mathbf{k}, c) \equiv \tilde{w}_{\text {prm }}(\mathbf{k}, c)$ (Table 3) [60], and (iii) $\tilde{w}_{\text {tot }}(\mathbf{k}, c, T) \equiv \tilde{w}_{\text {prm }}(\mathbf{k}, c)+\tilde{w}_{\text {mag }}(\mathbf{k}, c, T)(12)$. The results of such calculations are shown in Fig. 4.

In Figs $4, a, b$, one can see that, for both wave-vectors, the function $I_{\mathrm{SRo}}(\mathbf{k}, c, T)$ has the well-known form predicted by the KCM theory [1013], assuming that $\tilde{w}_{\text {tot }}(\mathbf{k})=$ const . A maximum (minimum) of the diffuse-scattering intensities at the $\mathbf{k}_{X}\left(\mathbf{k}_{\Gamma}\right)$ point lies at the concentration $c=1 / 2$ and decreases (increases) with increasing $T$, obeying a trivial law. 

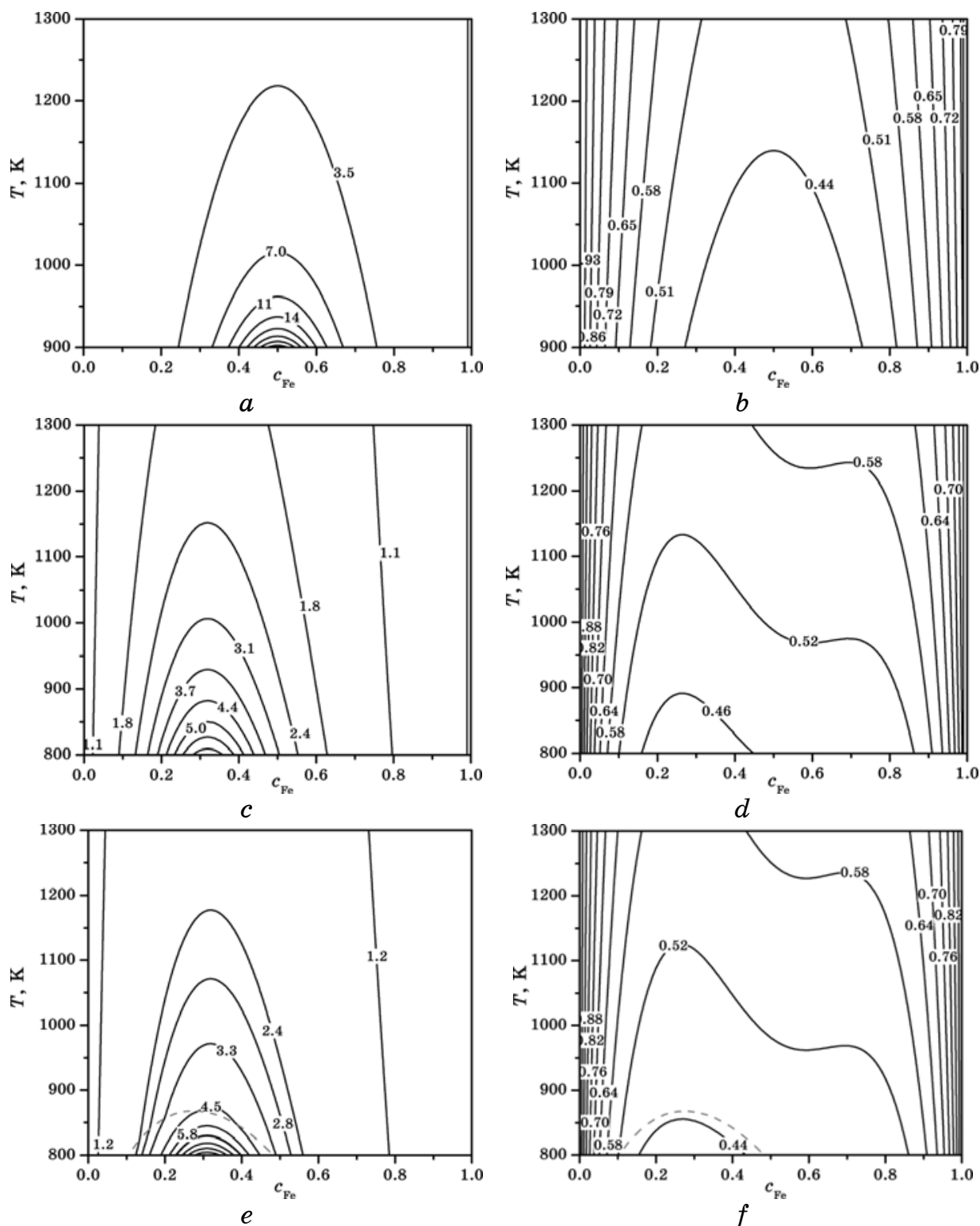

Fig. 4. The $(T-c)$-dependences $I_{\mathrm{SRO}}(\mathbf{k}, c, T)$ (in [Laue units]) at the high-symmetry points within the $1^{\text {st }} B Z$ for f.c.c.-Ni-Fe alloys: superstructural $X(001)$ and Bragg's 'fundamental' $\Gamma(000) ;(a) \tilde{w}_{\text {prm }}\left(\mathbf{k}_{X}\right)=-0.3 \mathrm{eV}$ and $(b) \tilde{w}_{\text {prm }}\left(\mathbf{k}_{\Gamma}\right)=$ $=0.5 \mathrm{eV}[10-13] ;(c) \tilde{w}_{\mathrm{prm}}\left(\mathbf{k}_{X}\right)=\tilde{w}_{\mathrm{prm}}\left(\mathbf{k}_{X}, c\right)$ and $(d) \tilde{w}_{\mathrm{prm}}\left(\mathbf{k}_{\Gamma}\right)=\tilde{w}_{\mathrm{prm}}\left(\mathbf{k}_{\Gamma}, c\right)(\mathrm{Ta}-$ ble 3) [60]; $(e) \tilde{w}_{\text {tot }}\left(\mathbf{k}_{X}, c, T\right)$ and $(f) \tilde{w}_{\text {tot }}\left(\mathbf{k}_{\Gamma}, c, T\right)(12)$. In $(e),(f)$, dotted lines are the Curie points' curve of the magnetic phase transitions, $T_{C}(c)$, calculated in accordance with (16). The calculation results according to (14) are not presented because they are almost the same as for (12). 
In the second case shown in Figs $4, c, d$, when $\tilde{w}_{\text {tot }}(\mathbf{k}, c) \equiv \tilde{w}_{\text {prm }}(\mathbf{k}, c)$, a maximum (minimum) of the diffuse-scattering intensity, $I_{\mathrm{SRO}}(\mathbf{k}, c, T)$, is shifted to the composition of $c \cong 1 / 3$ for $\mathbf{k}_{X}$ or $c \cong 1 / 4$ for $\mathbf{k}_{\Gamma}$, respectively, due to some competition of the addendums, $c(1-c) \beta \tilde{w}_{\mathrm{prm}}(\mathbf{k}, c)$ and 1 , in denominator of the KCM formula (1).

A special attention should be given to the third case presented in Figs $4, e, f$, where the total 'mixing' energies' Fourier components are $(T-c)$ dependent functions, $\tilde{w}_{\text {tot }}(\mathbf{k}, c, T)$ (12). As can be seen, the relation $\partial I_{\mathrm{SRO}}\left(\mathbf{k}_{X}\right) /\left.(\partial T \partial c)\right|_{T<T_{C}}>\partial I_{\mathrm{SRO}}\left(\mathbf{k}_{X}\right) /\left.(\partial T \partial c)\right|_{T>T_{C}}$ is satisfied and again indicates that, within the FMS $(T-c)$-domain, the atomic $L 1_{2}$-type SRO state is stabilized with respect to its PMS region. Apparently, taking into account the magnetic interactions does not change the total diffuse-scattering intensity pattern but only increases its absolute value (for both $\mathbf{k}_{X}$ and $\mathbf{k}_{\Gamma}$ ) within the FMS state of an alloy.

Let us now analyse the diffuse scattering from f.c.c. ${ }^{62} \mathrm{Ni}_{0.765} \mathrm{Fe}_{0.235}$ solid solution, using the statistical-thermodynamics model presented in Sec. 2. The diffuse-scattering patterns from such an alloy were studied in details experimentally by the elastic diffuse scattering of thermal neutrons [79, $84,85]$. The data obtained in those studies were repeatedly used in developing and testing of different theoretical models and approximations for the evaluation of interatomic-interaction energies [30-36, 79]. Table 5 shows the total 'mixing' energies for f.c.c. ${ }^{62} \mathrm{Ni}_{0.765} \mathrm{Fe}_{0.235}$ Permalloy estimated as 'effective' ones in certain approaches with using the different approximations [30, 33, 36, 79]. The theoretical data are presented for several isothermal-annealing temperatures, $T_{a}$, in accordance with [79, 85]. As can be seen from Table 5, the values of total 'mixing' energies significantly differ, depending on the models used for their calculation. For ease of further analysis, we have recalculated the Fourier components of those real-space energies. Thus, using the data shown in Tables 3 and 4 as well as the 'mixing' energies for different coordination shells in a real space, $w_{\text {tot }}\left(\mathbf{R}-\mathbf{R}^{\prime}, T\right)$, from Table 5 and applying the Fourier transform (3), the 'mixing' energies' Fourier components, $\tilde{w}_{\text {tot(prm) }}(\mathbf{k})$, for quasi-wave vectors $\mathbf{k}$ within the $1^{\text {st }} B Z$, namely, $\mathbf{k}_{X}, \Delta\left(\mathbf{k}_{X} \rightarrow \mathbf{k}_{\Gamma}\right)$ and $\mathbf{k}_{\Gamma}$, are calculated.

For each set of 'mixing' energies, the temperature of the absolute loss of stability with respect to the formation of concentration waves with the quasi-wave vector $\mathbf{k}_{X}$ is calculated, according to the formula [4-7]:

$$
T_{\mathrm{inst}} \simeq-c(1-c) \tilde{w}_{\mathrm{tot}}\left(\mathbf{k}_{X}\right) / k_{B} .
$$

The results of such calculations are presented in Table 6. From Table 6, one can immediately see that, from all instability temperatures, $T_{\text {inst }}$, only those, which are calculated using the data extracted from [33] $\left({ }^{1} \mathrm{CFM}\right.$ : $\left.T_{a}=745 \mathrm{~K}, 780 \mathrm{~K}\right)$, [36] ( ${ }^{1} \mathrm{GEM}$ : for all thermal treatments) and in our model, are agreed reasonably with the experimental value of the order- 
disorder phase transformation temperature, $T_{K} \approx 771-773 \mathrm{~K}$. The worse results (with deviation of $\pm \mathbf{1 5 0} \mathrm{K}$ ) are obtained for the interaction energies taken from [33] ( $\left.{ }^{1} \mathrm{CFM}: T_{a}=808 \mathrm{~K}, 958 \mathrm{~K} ;{ }^{2,3} \mathrm{CFM}: T_{a}=780 \mathrm{~K}\right)$ and for [36] (SM: for all thermal treatments). $T_{\text {inst }}$ calculated by using the data from other references poorly match the experimental value of $T_{K}$.

The values of the 'mixing' energies obtained using the KCM [79] and LIMCM [30] approaches (see Tables 5 and 6) are underestimated comparing with the CFM [33], SM and GEM [36] data as well as with the present-work results and, therefore, give significantly lower values of the instability temperatures (Table 6). One can also conclude that the main reason of such a disagreement is caused by the use of incorrect values of the Warren-Cowley SRO parameters, $\alpha\left(\mathbf{r}_{l m n}\right)$, calculated in [79] (especially for the FMS ( $T-c)$-domain), neglecting the magnetic contribution and its temperature and concentration dependences (see, e.g., Eqs (12) or (14) along with (1) and (2)). It should also be mentioned that the assumption made in [34-37] about separating the interatomic interaction into two contributions, the short-range and long-range ones (with consecutive expansion by a small parameter ' $\gamma$ '), is quite reasonable; however, at the same time, it is not so evident as in the suggested models, where the total 'mixing' energies are given in the form of (12) or (14). In such cases, the total 'mixing' energies consist of both the 'short-range' ('electrochemical' and magnetic) and 'longrange' ('strain-induced') energy contributions in their explicit forms.

\subsection{Kinematics of the Diffuse Scattering of Radiations in a (Para)Magnetic F.C.C.- $\mathrm{Ni}_{0.765} \mathrm{Fe}_{0.235}$ Permalloy}

Let us consider another application of the models developed in Sec. 2 by way of illustration of detailed calculations of the diffuse scattering intensities for f.c.c. ${ }^{62} \mathrm{Ni}_{0.765} \mathrm{Fe}_{0.235}$ Permalloy. With such a goal, at the beginning, we calculate the temperature dependence of the spontaneous magnetizations for both interacting magnetic subsystems, $\sigma_{\mathrm{Fe}}(T)$, $\sigma_{\mathrm{Ni}}(T)$, using the SCF + MSCF approximations (11) and the interpolation scheme (13) (with the admissible adjustable parameters, $\kappa_{\mathrm{Ni}}, \kappa_{\mathrm{Fe}}$ ).

The results of such calculations are shown in Fig. 5, where one can see that the results on the temperature dependence of spontaneous magnetizations obtained in both approximations in accordance with Eqs (11) and (13) are in a good agreement with each other within the whole temperature interval $\left(0, T_{C}\right)$. Slight disagreements for Ni-subsystem magnetization, $\sigma_{\mathrm{Ni}}(T)$, including its nonphysical value $>1$, appeared at $T \in(0,450 \mathrm{~K})$, is caused by the inaccuracy of Eq. (13). Thus, using the values of $\sigma_{\mathrm{Fe}}(T)$, $\sigma_{\mathrm{Ni}}(T)$ (Fig. 5) and the 'paramagnetic' 'mixing' energies, $\tilde{w}_{\mathrm{prm}}(\mathbf{k}, c)$ (Table 3), as well as the 'exchange' 'integrals', $\tilde{J}_{\alpha \alpha^{\prime}}(\mathbf{k})$ (Table 4), one can calculate the $T$-dependence of total 'mixing' energies' Fourier components, $\tilde{w}_{\text {tot }}(\mathbf{k}, c, T)$, in accordance with Eqs (12) and (14) for $c=0.235$. 


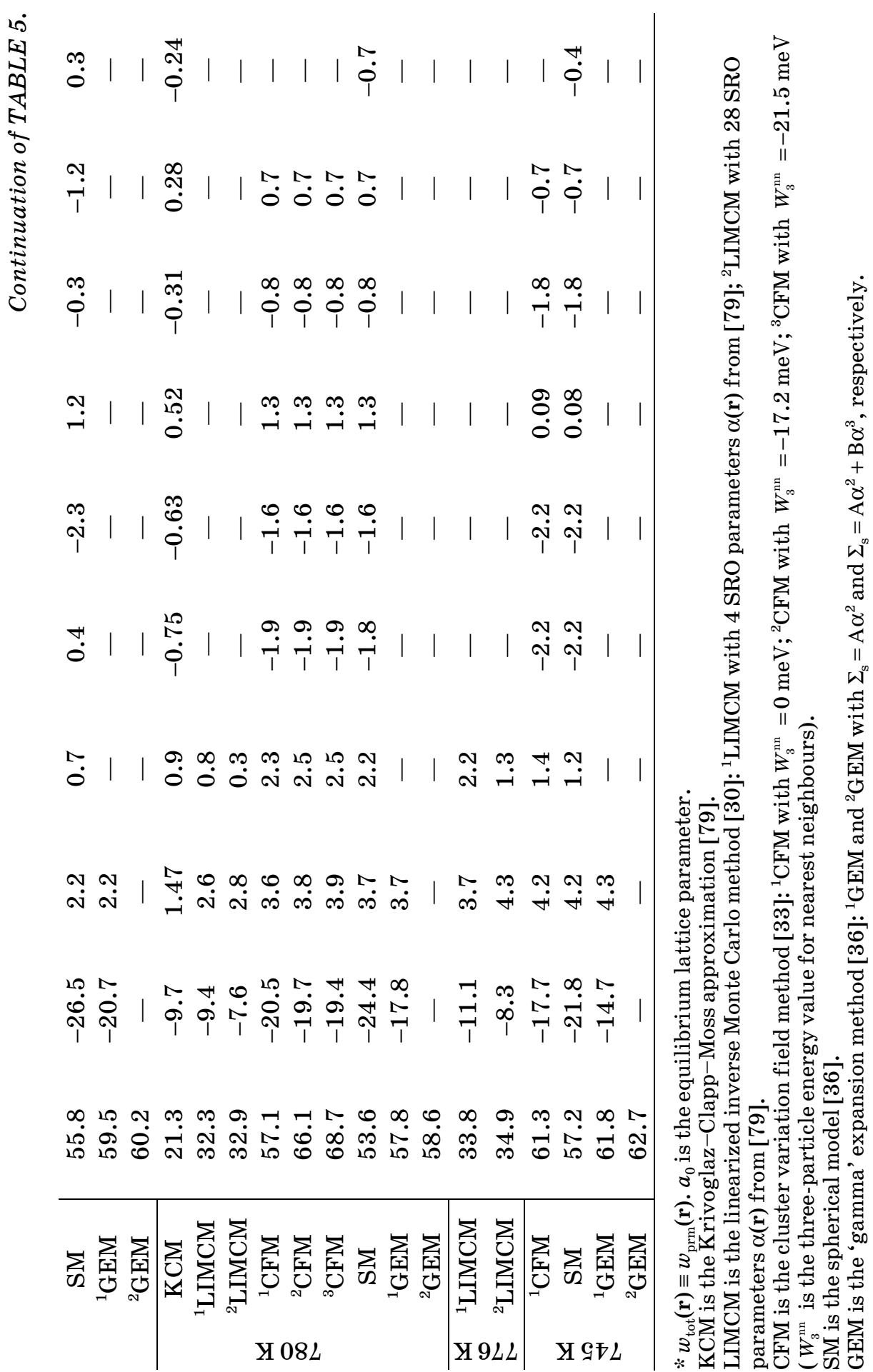


TABLE 6. The total ('effective') 'mixing' energies' Fourier components, $\tilde{w}_{\text {tot }}(\mathbf{k})$ (in [meV]), calculated using the data for f.c.c. ${ }^{62} \mathrm{Ni}_{0.765} \mathrm{Fe}_{0.235}$ Permalloy from Tables 3, 4 and 5 for quasi-wave vectors $\mathbf{k}$ within the $1^{\text {st }} B Z$ : near the 'fundamental' $\Gamma(000)$ point, $\Delta\left(\mathbf{k} \rightarrow \mathbf{k}_{\Gamma}\right)$; at the 'fundamental' $\Gamma(000)$ point precisely, $\mathbf{k}_{\Gamma}$; for the superstructural $X(100)$ point, $\mathbf{k}_{X}$. The absolute instability temperatures, $T_{\text {inst }}$ (in $[\mathrm{K}])$, calculated with (19), using the values of $\tilde{w}_{\text {tot }}^{\text {eff }}\left(\mathbf{k}_{X}\right)$, are presented too.

\begin{tabular}{|c|c|c|c|c|c|c|}
\hline Theory & Energies $T_{a}, \mathrm{~K}$ & 958 & 808 & 780 & 776 & 745 \\
\hline \multirow{3}{*}{$\begin{array}{c}\text { KCM, } \\
\text { [79] }\end{array}$} & $\tilde{w}_{\text {tot }}^{\text {eff }}\left(\mathbf{k} \rightarrow \mathbf{k}_{\Gamma}\right)$ & 338.1 & 225.6 & 241.1 & - & - \\
\hline & $\tilde{w}_{\text {tot }}^{\text {eff }}\left(\mathbf{k}_{X}\right)$ & -135.6 & -158.8 & -152.8 & - & - \\
\hline & $T_{\text {inst }}$ & 282.9 & 331.3 & 318.7 & - & - \\
\hline \multirow{3}{*}{$\begin{array}{l}{ }^{1} \mathrm{LIMCM}, \\
{[30]}\end{array}$} & $\tilde{w}_{\text {tot }}^{\text {eff }}\left(\mathbf{k} \rightarrow \mathbf{k}_{\Gamma}\right)$ & 449.4 & 273.6 & 403.2 & 454.2 & - \\
\hline & $\tilde{w}_{\text {tot }}^{\text {eff }}\left(\mathbf{k}_{X}\right)$ & -171.4 & -192.0 & -196.8 & -205.0 & - \\
\hline & $T_{\text {inst }}$ & 357.5 & 400.5 & 410.5 & 427.6 & - \\
\hline \multirow{3}{*}{$\begin{array}{l}{ }^{2} \text { LIMCM, } \\
\text { [30] }\end{array}$} & $\tilde{w}_{\text {tot }}^{\text {eff }}\left(\mathbf{k} \rightarrow \mathbf{k}_{\Gamma}\right)$ & 493.8 & 361.8 & 420.0 & 487.8 & - \\
\hline & $\tilde{w}_{\text {tot }}^{\text {eff }}\left(\mathbf{k}_{X}\right)$ & -179.8 & -193.4 & -196.0 & -208.2 & - \\
\hline & $T_{\text {inst }}$ & 375.0 & 403.4 & 408.8 & 434.3 & - \\
\hline \multirow{3}{*}{$\begin{array}{l}{ }^{1} \mathrm{CFM}, \\
{[33]}\end{array}$} & $\tilde{w}_{\text {tot }}^{\text {eff }}\left(\mathbf{k} \rightarrow \mathbf{k}_{\Gamma}\right)$ & 847.4 & 708.8 & 683.8 & - & 661.7 \\
\hline & $\tilde{w}_{\text {tot }}^{\text {eff }}\left(\mathbf{k}_{X}\right)$ & -306.2 & -425.6 & -378.6 & - & -377.6 \\
\hline & $T_{\text {inst }}$ & 638.7 & 887.8 & 789.7 & - & 787.7 \\
\hline \multirow{3}{*}{$\begin{array}{l}{ }^{2} \mathrm{CFM}, \\
{[33]}\end{array}$} & $\tilde{w}_{\text {tot }}^{\text {eff }}\left(\mathbf{k} \rightarrow \mathbf{k}_{\Gamma}\right)$ & - & - & 803.8 & - & - \\
\hline & $\tilde{w}_{\text {tot }}^{\text {eff }}\left(\mathbf{k}_{X}\right)$ & - & - & -409 & - & - \\
\hline & $T_{\text {inst }}$ & - & - & 853.1 & - & - \\
\hline \multirow{3}{*}{$\begin{array}{c}{ }^{3} \mathrm{CFM}, \\
{[33]}\end{array}$} & $\tilde{w}_{\text {tot }}^{\text {eff }}\left(\mathbf{k} \rightarrow \mathbf{k}_{\Gamma}\right)$ & - & - & 839.2 & - & - \\
\hline & $\tilde{w}_{\text {tot }}^{\text {eff }}\left(\mathbf{k}_{X}\right)$ & - & - & -418.4 & - & - \\
\hline & $T_{\text {inst }}$ & - & - & 872.7 & - & - \\
\hline \multirow{3}{*}{$\begin{array}{l}\text { SM, } \\
{[36]}\end{array}$} & $\tilde{w}_{\text {tot }}^{\text {eff }}\left(\mathbf{k} \rightarrow \mathbf{k}_{\Gamma}\right)$ & 815.0 & 640.4 & 605.2 & - & 575.4 \\
\hline & $\tilde{w}_{\text {tot }}^{\text {eff }}\left(\mathbf{k}_{X}\right)$ & -314.6 & -441.2 & -385.2 & - & -384.9 \\
\hline & $T_{\text {inst }}$ & 656.2 & 920.297 & 803.5 & - & 802.8 \\
\hline \multirow{3}{*}{$\begin{array}{l}{ }^{1} \mathrm{GEM}, \\
{[36]}\end{array}$} & $\tilde{w}_{\text {tot }}^{\text {eff }}\left(\mathbf{k} \rightarrow \mathbf{k}_{\Gamma}\right)$ & 796.8 & 642.6 & 675.6 & - & 756.6 \\
\hline & $\tilde{w}_{\text {tot }}^{\text {eff }}\left(\mathbf{k}_{X}\right)$ & -372.8 & -379.8 & -367.6 & - & -369.8 \\
\hline & $T_{\text {inst }}$ & 777.6 & 792.2 & 766.8 & - & 771.4 \\
\hline \multirow{3}{*}{$\begin{array}{l}{ }^{2} \mathrm{GEM}, \\
{[36]}\end{array}$} & $\tilde{w}_{\text {tot }}^{\text {eff }}\left(\mathbf{k} \rightarrow \mathbf{k}_{\Gamma}\right)$ & 744.0 & 722.4 & 703.2 & - & - \\
\hline & $\tilde{w}_{\text {tot }}^{\text {eff }}\left(\mathbf{k}_{X}\right)$ & -248.0 & -240.8 & -234.4 & - & - \\
\hline & $T_{\text {inst }}$ & 517.3 & 502.3 & 488.9 & - & - \\
\hline \multirow{9}{*}{$\begin{array}{l}\text { present } \\
\text { work }\end{array}$} & $\tilde{w}_{\mathrm{prm}}\left(\mathbf{k} \rightarrow \mathbf{k}_{\Gamma}\right)$ & 458.7 & 458.7 & 458.7 & 458.7 & 458.7 \\
\hline & $\tilde{w}_{\mathrm{prm}}\left(\mathbf{k}_{\Gamma}\right)$ & 500.0 & 500.0 & 500.0 & 500.0 & 500.0 \\
\hline & $\tilde{w}_{\mathrm{prm}}\left(\mathbf{k}_{X}\right)$ & -308.0 & -308.0 & -308.0 & -308.0 & -308.0 \\
\hline & $* \tilde{w}_{\text {mag }}\left(\mathbf{k}_{\Gamma}\right)$ & 0 & 61.4 & 89.8 & 93.8 & 123.6 \\
\hline & $\tilde{w}_{\mathrm{mag}}\left(\mathbf{k}_{X}\right)$ & 0 & -20.5 & -29.9 & -31.3 & -41.2 \\
\hline & $\tilde{w}_{\text {tot }}\left(\mathbf{k} \rightarrow \mathbf{k}_{\Gamma}\right)$ & 458.7 & 520.1 & 548.5 & 552.5 & 582.3 \\
\hline & $\tilde{w}_{\text {tot }}\left(\mathbf{k}_{\Gamma}\right)$ & 500.0 & 561.4 & 589.8 & 593.8 & 623.6 \\
\hline & $\tilde{w}_{\text {tot }}\left(\mathbf{k}_{X}\right)$ & -308.0 & -328.5 & -337.9 & -339.3 & -349.2 \\
\hline & $T_{\text {inst }}$ & 745 & 745 & 745 & 745 & 745 \\
\hline
\end{tabular}

$T_{K}=771 \mathrm{~K}$ is the experimental Kurnakov temperature value reported in [84].

The title abbreviations of theoretical methods are in Table 5 .

* For 'exchange' interactions, which are the 'direct' and limited to the $1^{\text {st }}$ coordination shell only, $\tilde{w}_{\text {mag }}\left(\mathbf{k}_{\Gamma}\right)=\tilde{w}_{\text {mag }}\left(\mathbf{k} \rightarrow \mathbf{k}_{\Gamma}\right)$. Because the estimated Curie point of f.c.c. ${ }^{62} \mathrm{Ni}_{0.765} \mathrm{Fe}_{0.235}$ is $T_{C}=862 \mathrm{~K}$, for energies calculated at $T_{a}=958 \mathrm{~K}$, it is necessary to replace $\tilde{w}_{\text {tot }}^{\text {eff }}(\mathbf{k}) \rightarrow \tilde{w}_{\mathrm{prm}}^{\text {eff }}(\mathbf{k})$. 


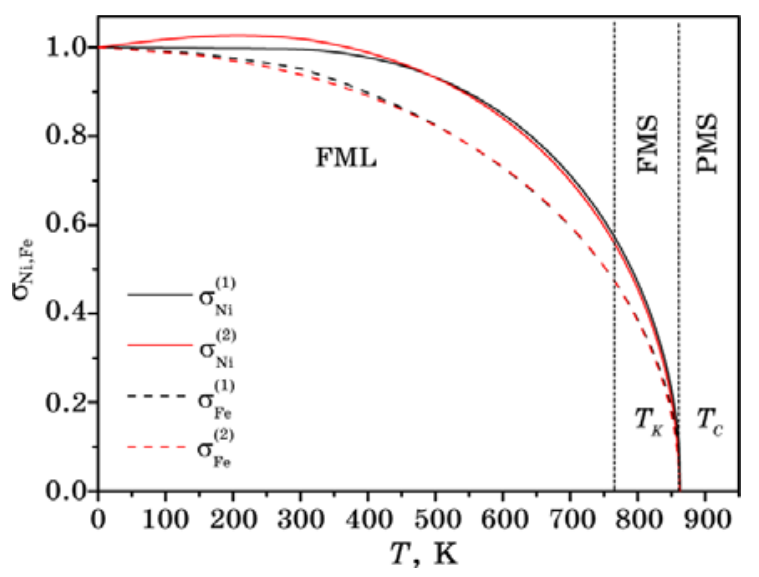

Fig. 5. The temperature dependence of the spontaneous magnetization for $\alpha$ th $(\alpha=\mathrm{Ni}, \mathrm{Fe})$ subsystem, $\sigma_{\alpha}(T)$, calculated for f.c.c. $-\mathrm{Ni}_{0.765} \mathrm{Fe}_{0.235}$ alloy without the atomic LRO; $\sigma_{\alpha}^{(1)}$ is extracted by solving Eqs (11), $\sigma_{\alpha}^{(2)}$ is extracted with use of $(13)\left(\kappa_{\mathrm{Ni}} \approx 3 / 4, \kappa_{\mathrm{Fe}} \approx 1 / 2\right)$. In calculations, the 'exchange' 'integrals' Fourier components, $\tilde{J}_{\alpha \alpha^{\prime}}(\mathbf{k})$, are chosen for values of $s_{\mathrm{Ni}}=1 / 2, s_{\mathrm{Fe}}=3 / 2$ (Table 4). Note that, at the Kurnakov point precisely, $T_{K}$, the functions $\sigma_{\alpha}^{(1,2)}(T)$ should demonstrate the jumps, $\Delta \sigma_{\alpha}^{(1,2)}\left(T_{K}\right)$, due to the jump of the atomic LRO parameter, $\Delta \eta\left(T_{K}\right)$, and, in such a case, the functions $\sigma_{\alpha}^{(1,2)}\left(T \in\left(0, T_{K}\right)\right)$ must be calculated in accordance with the more general SCF + MSCF equations with respect to (11), which can be found elsewhere [56-61]. Since here, we are interested in consideration of the (meta)stable FMS region only, such a reasonable correction in the $\sigma_{\alpha}^{(1,2)}(T)$ functions may be omitted for $T \in\left(T_{K}, T_{C}\right.$ ) (and even for the quenched 'high-temperature' SRO state fixed at $\left.T \in\left(0, T_{K}\right)\right)$. Here, FML, FMS and PMS are the ferromagnetic atomic LRO, ferromagnetic atomic SRO and paramagnetic atomic SRO regions, respectively. The estimated Curie temperature, $T_{C}$, is equal to $862 \mathrm{~K}$.

Next, substituting the dependence $\tilde{w}_{\text {tot }}(\mathbf{k}, c, T)$ into the KCM formula (1) (assuming $D \equiv 1$ in (2)), it is possible to calculate the temperature dependence of the diffuse scattering intensities, $I_{\mathrm{SRO}}(\mathbf{k}, c, T)$, for quasiwave vectors $\mathbf{k}$ within the $1^{\text {st }} B Z$ such as $\mathbf{k}_{X}, \Delta\left(\mathbf{k}_{X} \rightarrow \mathbf{k}_{\Gamma}\right)$ and $\mathbf{k}_{\Gamma}$. The results of such calculations and the recalculated data (using the 'mixing' energies taken from [30, 33, 36, 79] and the data presented in Tables 5 and 6) are shown in Fig. 6 in comparison with the experimental results reported in $[79,84,85]$.

From Fig. 6, one can see that the temperature dependence of the diffuse scattering intensity (in accordance with both approximations (12) and (14)) for the dominant superstructural point $\mathbf{k}_{X}, I_{\mathrm{SRO}}\left(\mathbf{k}_{X}, T\right)$ are in an excellent agreement with the experimental data reported in $[79,84$, 85]. It is also visible that the 'non-analyticity' of the interatomicinteraction energies' Fourier component at $\mathbf{k}=\mathbf{k}_{\Gamma}$ (see Refs in $[58,60]$ ) leads to the difference in the diffuse scattering intensities for the qua- 

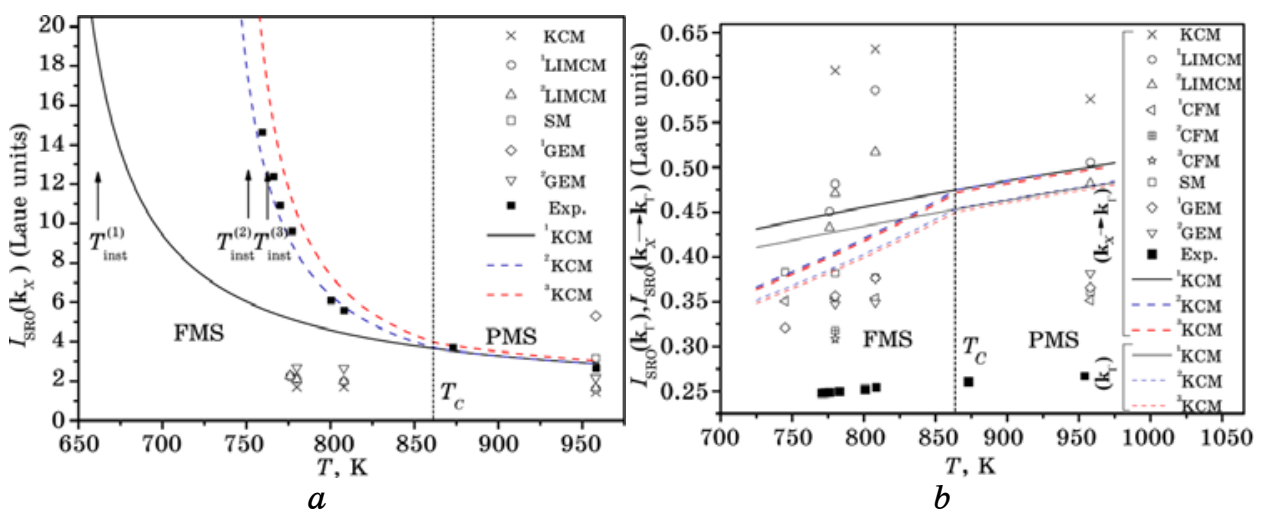

Fig. 6. The temperature dependence of the diffuse scattering intensities, $I_{\text {SRO }}(\mathbf{k}, T)$ in [Laue units], for f.c.c. ${ }^{62} \mathrm{Ni}_{0.765} \mathrm{Fe}_{0.235}$ Permalloy, for quasi-wave vectors $\mathbf{k}$ within the $1^{\text {st }} B Z: \mathbf{k}_{X}, \Delta\left(\mathbf{k}_{X} \rightarrow \mathbf{k}_{\Gamma}\right)$ and $\mathbf{k}_{\Gamma}$. The data in [30, 33, 36, 79] are obtained theoretically; - - the experimental data on $I_{\mathrm{SRO}}(\mathbf{k})$ from [84] (for $808 \mathrm{~K}$ from [85], for 873 and $958 \mathrm{~K}$ from [79]). ${ }^{\mathrm{n}} \mathrm{KCM}(\mathrm{n}=1,2,3)$ - the results of a given work: ${ }^{1} \mathrm{KCM}$ - a classical approximation with an assumption of $\tilde{w}_{\text {tot }}(\mathbf{k}) \equiv \tilde{w}_{\text {prm }}(\mathbf{k})=$ const [10-13], ${ }^{2} \mathrm{KCM}$ and ${ }^{3} \mathrm{KCM}$ are based on Eq. (12) and Eq. (14), respectively. As assumed here, $\tilde{w}_{\text {prm }}\left(\mathbf{k}_{X}\right)=-0.30 \mathrm{eV}, \tilde{w}_{\text {prm }}\left(\mathbf{k}_{\Gamma}\right)=0.50$ $\mathrm{eV}$, and $\tilde{w}_{\text {prm }}\left(\mathbf{k}_{X} \rightarrow \mathbf{k}_{\Gamma}\right)=0.46 \mathrm{eV}$ (see also Tables 3 and 6) [60]. Here, the results of other theories should be addressed to KCM [79], ${ }^{1}$ LIMCM [30], ${ }^{2}$ LIMCM [30], SM [36], ${ }^{1}$ GEM [36], ${ }^{2}$ GEM [36], ${ }^{1}$ CFM [33], ${ }^{2}$ CFM [33], and ${ }^{3} \mathrm{CFM}$ [33]. $T_{\text {inst }}$ is the absolute stability-loss temperature: $T_{\text {inst }}^{(1,2,3)}=626,745$, $755 \mathrm{~K}$. The data, for which $T_{\text {inst }}>745 \mathrm{~K}$, are not shown for lucidity. The estimated Curie temperature, $T_{C}$, is equal to $862 \mathrm{~K}(16)$.

si-wave vectors $\mathbf{k}_{\Gamma}$ and $\Delta\left(\mathbf{k}_{X} \rightarrow \mathbf{k}_{\Gamma}\right)$. (Taking into account such a difference is crucially important for the correct interpretation of the diffraction data on isostructural and spinodal decompositions in solid solutions.)

The obvious disagreement between the calculated temperature dependence of the diffuse scattering intensities for 'fundamental' Bragg's (structural) reflection, $I_{\mathrm{SRO}}\left(\mathbf{k}_{\Gamma}, T\right)$, and the estimated dependences $I_{\mathrm{SRO}}\left(\mathbf{k} \rightarrow \mathbf{k}_{\Gamma}, T\right)$ (obtained by means of the extrapolation of experimental data taken from Refs $[79,84,85])$ is most likely due to the experimental difficulties appeared in the measurement and during separation of the diffuse scattering intensity (because of the strong coherent scattering as well as the scattering by phonons, magnons, and other nonlocalized excitations) in the vicinity of the 'fundamental' $\Gamma(000)$ point. In addition, the diffuse scattering intensities for all quasi-wave vectors significantly deviate from the KCM prediction (at assumption of $\tilde{w}_{\text {tot }}(\mathbf{k})=$ const $)$, when the temperature decreases from PMS to FMS regions. At the same time, the results of the suggested models and the classical KCM approach [10-13] are matched completely within the 
PMS region for the alloy at issue $\left(T>T_{C}\right)$.

\subsection{Constant $D$ in the KCM Formula for F.C.C.-Ni-Fe Alloys}

Finally, let us analyse in this Section the constant $D(2)$ entered into the KCM formula (1). In the theoretical works [30-36] and experimental studies $[79,84,85]$, much attention was paid to the analysis of the normalization constant $D(2)$. In particular, the main conclusion was about the strong concentration and temperature dependences of $D$, $D(T, c)$, and the significant deviation of $D$ from $D \equiv 1$ with decreasing temperature. As a result, the authors claim that the KCM formula (1) cannot be used adequately for the analysis of f.c.c.-Ni-Fe alloys at temperatures close to the Kurnakov points and within the FMS region. Their argumentation is based solely on the fact that the KCM approach is adequate if and only if the condition is satisfied as follows: $\tilde{w}_{\text {tot }}\left(\mathbf{k}_{X}\right) /\left(k_{B} T\right) \ll 1$. However, as can be seen from Fig. 6 , there is no necessity in such a conclusion. Let us consider this point in detail fitting with observed data.

Using the total 'mixing' energies' Fourier components' representation in the form of (12) with the factor $D(2)$ for f.c.c.-Ni-Fe alloys, one can carry out the integration over the $1^{\text {st }} B Z$ in order to obtain the ( $T-$ $c$ )-dependence of $D=D(T, c)$. The results are shown in Fig. 7. For such a calculation, three cases are considered as follow: (i) $\tilde{w}_{\text {prm }}(\mathbf{k})=$ const (as original KCM assumption [10-13]), (ii) $\tilde{w}_{\text {prm }}(\mathbf{k})=\tilde{w}_{\text {prm }}(\mathbf{k}, c)$ (based on Table 3) [60], and (iii) $\tilde{w}_{\text {tot }}(\mathbf{k})=\tilde{w}_{\text {tot }}(\mathbf{k}, c, T)$ (based on Eqs (12) or (14) in line with Tables 3 and 4).

As can be seen from Fig. 7, the constant $D$ deviates slightly from the value $D=1$ within the whole $(T-c)$-domain of f.c.c.-Ni-Fe alloys with the atomic SRO. There is only the exception near the Invar composition region $\left(c_{\mathrm{Fe}} \cong 0.65\right)$. This unconventional behaviour is likely due to the competition between the $(T-c)$-dependent energy contributions such as Eq. (12) (within the PMS region) multiplied by the concentrationtemperature factor $c(1-c) \beta$ and 1 in denominator in Eq. (2). As a result, within the Invar composition region, it is necessary to consider the correction of $D \neq 1$ into the KCM formula (1). In any event, the conclusion about the constant $D$ reported in [30-37, 79, 84, 85] does not correspond to validity because of fact that the factor $D$ tends strongly to $D=1$ within the FMS region, compared with the PMS one (Figs $7, b$, $c)$. Moreover, in this case, the ratio $\tilde{w}_{\text {prm }}(\mathbf{k}) /\left(k_{B} T\right) \ll 1[10-13]$ is not violated, and the ratio $\tilde{w}_{\text {tot }}(\mathbf{k}) /\left(k_{B} T\right)$ can be even compared with 1 .

\section{CONCLUSIONS}

In a given work, within the scope of the SCF and MSCF approximations 


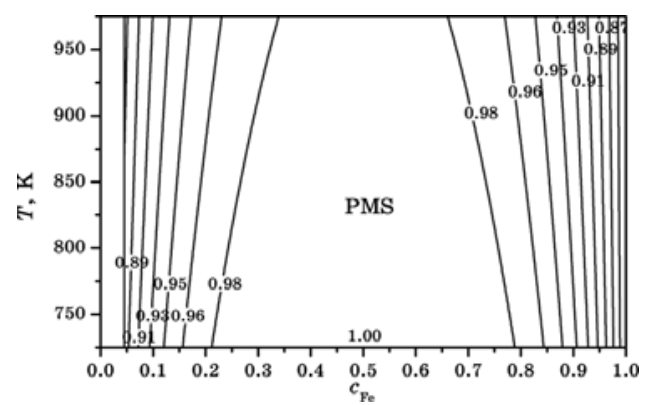

$a$
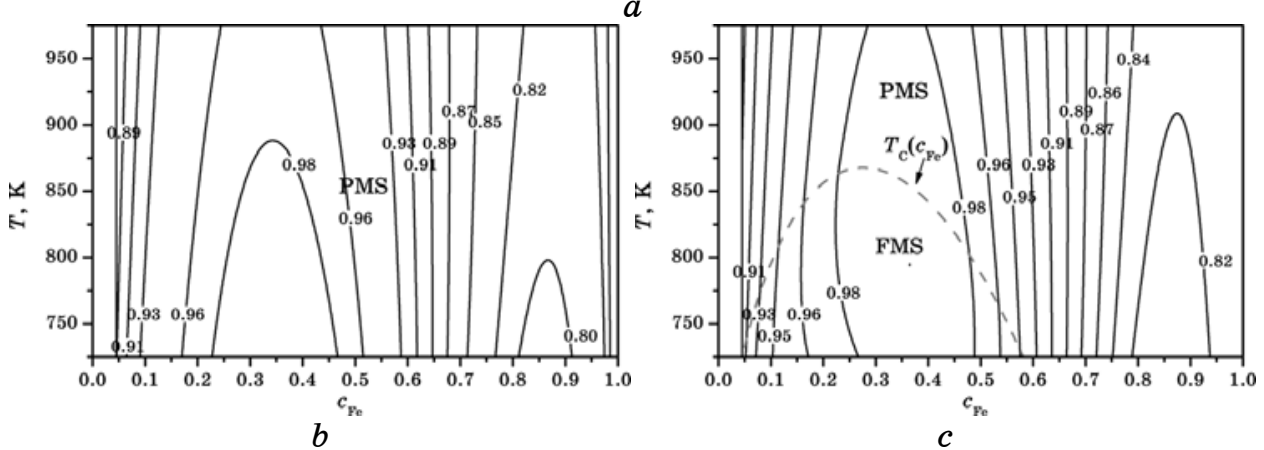

Fig. 7. The $(T-c)$-dependence of the normalization 'constant', $D$ (namely, $D=D(c, T))$, in Eq. (2) calculated at several assumptions: $(a) \tilde{w}_{\text {prm }}(\mathbf{k})=$ const [10-13], (b) $\tilde{w}_{\mathrm{prm}}(\mathbf{k})=\tilde{w}_{\mathrm{prm}}(\mathbf{k}, c) \quad\left(\right.$ Table 3) [60], (c) $\tilde{w}_{\text {tot }}(\mathbf{k})=\tilde{w}_{\text {tot }}(\mathbf{k}, c, T) \quad(\mathrm{see}$ Eqs (12) or (14) and Tables 3 and 4). Here, $c \equiv c_{\mathrm{Fe}}$. The function $T_{C}\left(c_{\mathrm{Fe}}\right)$ is calculated according to Eq. (16).

[56-61], on an example of detailed consideration of disordered f.c.c.$\mathrm{Ni}-\mathrm{Fe}$ alloy with the atomic SRO, the statistical-thermodynamics model of the substitutional atomic SRO states for binary (para)magnetic alloys based on the cubic Bravais crystal lattice with two magnetic constituents is improved. In addition, a simple approximation representing the total 'mixing' energies' Fourier components as a polynomial temperature-dependent function of $3^{\text {rd }}$ order within the magnetic $(T-c)$-domain of an alloy is suggested. As a result, the interpolating relations for the $(T-c)$-dependence of the diffuse scattering intensities are obtained on the basis of the classical KCM formula and representing the total 'mixing' energies' Fourier components as a sum of three energy contributions of different natures, namely, the 'shortrange' and 'direct' 'electrochemical' and 'exchange' (magnetic) interactions as well as the 'long-range' and 'indirect' 'strain-induced' interaction. In both cases, we have suggested the explicit form for $(T-c)$ dependence of the total 'mixing' energies (Eqs (12) and (14)) for f.c.c.$\mathrm{Ni}-\mathrm{Fe}$ alloys.

Using the statistical MC simulation technique and the Warren- 
Cowley SRO parameters extracted from the radiation diffuse scattering experiments [79-83], the local atomic configurations (and their Fourier transforms, i.e. diffuse scattering patterns) for f.c.c.-Ni-Fe alloys within the Permalloy, Elinvar and Invar compositions are obtained at temperatures above and below the Curie points, $T_{C}$. As shown, the diffuse scattering intensity at the superstructural quasiwave vector, $\mathbf{k}_{X}(001)$, significantly depends on temperature and composition of an alloy. This phenomenon testifies on the essential role of the alloy magnetism in thermodynamics of the atomic SRO states.

Within the scope of suggested models, we have calculated the $(T-c)$ dependence of the diffuse scattering intensities for two preferential quasi-wave vectors within the $1^{\text {st }} B Z$, namely, for the high-symmetry points-superstructural $\mathbf{k}_{X}(001)$ and 'fundamental' $\mathbf{k}_{\Gamma}(000)$. As a result, as shown unambiguously, taking into account the magnetic ('exchange') interactions in the statistical thermodynamics of disordered alloys leads to the significant deviation of the diffuse scattering intensity from its classical form governed by the KCM formula, which assumes the $(T-c)$-independence of the total 'mixing' energies. Such a deviation is mainly caused by the strong $(T-c)$-dependence of the magnetic 'mixing'-energies' contribution (Eqs (12) and (14)) within the magnetic domain of an alloy phase diagram as well as its strong influence on the atomic subsystem and vice versa.

Furthermore, we have carefully verified the accuracy of suggested models on an example of the prediction of the diffuse scattering intensities for f.c.c. ${ }^{62} \mathrm{Ni}_{0.765} \mathrm{Fe}_{0.235}$ Permalloy across its magnetic and paramagnetic domains with the atomic SRO. The results were compared with the most reliable data of the neutrons' diffuse scattering experiments $[79,84,85]$ as well as with the theoretical results reported before [30-36]. As a result, we have found an excellent agreement of both approximate models reported here with the experiments (Fig. 6).

Finally, within the scope of the suggested models, the normalization factor $D$, which enters into the KCM formula, has been estimated within the whole (para)magnetic $(T-c)$-domain of f.c.c.-Ni-Fe alloys with the atomic SRO. As shown, the constant $D$ does not significantly deviate from the value $D=1$ for the whole $(T-c)$-domain of (para)magnetic f.c.c.-Ni-Fe alloys, and within the magnetic region of an alloy, such a requirement is satisfied rigorously, compared with the paramagnetic state of the system at issue. As a result, we demonstrate that, in case of magnetic alloys, the numerous criticisms of the KCM formula as such expressed by many researchers over the last several decades are groundless for realistic simulation of interatomic interactions. Moreover, the correct consideration of magnetism (even within the scope of the simplified local magnetic-moments' model only) in the statistical thermodynamics of magnetic alloys is still making the KCM approach as a unique theoretical tool for precise evaluations of the interatomic 'mix- 
ing' energies in magnetically ordered mixed systems.

Therefore, as may be concluded, in many practical cases, it is not necessary to overestimate the relevance of both the interatomic correlation and the many-body interaction effects in statistical physics of disordered magnetic materials. Almost all reliable experimental features of the diffuse scattering of radiations can be easily explained and reasonably described within the scope of the simplest 'pairwise' interatomic-interactions' model solely and with using the conventional SCF and MSCF approximations, in particular, the classical KCM formula within the simple representation of the total 'mixing' energies' Fourier components in the form of (12) or (14).

In conclusion, one may suggest the possible applications of the suggested models for 'indirect' evaluation of the magnetic 'mixing' energies (or 'exchange' 'integrals') for atoms with magnetic moments in alloys by using the synchrotron $\mathrm{X}$-ray scattering technique only instead of the conventional neutron scattering methods [86-88]. Thus, (i) by measuring the temperature dependence of the diffuse scattering intensity, $I_{\mathrm{SRO}}\left(\mathbf{k}_{s}, T\right)$, within the paramagnetic and magnetic $(T-c)$ domains for the superstructural quasi-wave vector, $\mathbf{k}_{s}$, generating the dominant fluctuation concentration wave in a magnetic alloy with the atomic SRO, and (ii) by interpolating these data by the KCM formula (1), taking into account the representation by (12) or (14), it becomes possible to estimate theoretically a set of microscopic parameters of an alloy, including magnetic 'mixing' energies and corresponding 'exchange' 'integrals'.

We believe that the presented study may shed a fresh insight into the physics of substitutional atomic-SRO phenomena in conventional and up-to-date (para)magnetic alloys, revising several established conceptions in the statistical thermodynamics of solid solutions.

\section{ACKNOWLEDGEMENTS}

Authors of a given article are grateful to Dr. R. V. Chepulskii (Samsung Electronics, U.S.A.), Prof. B. Schönfeld (ETH, Switzerland), Prof. J. B. Staunton (Warwick University, U.K.), Dr. G. E. Ice (Oak Ridge National Laboratory, U.S.A.), Prof. S. Hata (Kyushu University, Japan), and Dr. F. Bley (France) for providing their own publications, communicating important references and stimulating discussions about atomic ordering in metallic alloys. One of the co-authors (S.M.B.) would like to thank the members of the Groupe de Physique des Matériaux (Université de Rouen, France) for their kind hospitality during his stay in 20062008 at the Rouen University as well as the Institute for Advanced Materials Science and Innovative Technologies (Vilnius, Lithuania) for partial financial support. Another co-author (I.V.V.) acknowledges the Groupe de Physique des Matériaux (Université de Rouen, France) too for 
partial financial support of a given work.

\section{REFERENCES}

1. M. A. Krivoglaz and A. A. Smirnov, The Theory of Order-Disorder in Alloys (London: Macdonald: 1965).

2. D. de Fontaine, Solid State Physics (Eds. H. Ehrenreich et al.) (New York: Academic Press: 1979), vol. 34, p. 73.

3. F. Ducastelle, Order and Phase Stability in Alloys (New York: Elsevier: 1991).

4. A. G. Khachaturyan, Progr. Mater. Sci., 22: 1 (1978).

5. A. G. Khachaturyan, Theory of Structural Transformations in Solids (Mineola, NY: Dover Publications Inc.: 2008).

6. M. A. Krivoglaz, X-Ray and Neutron Diffraction in Nonideal Crystals (Berlin: Springer: 1996).

7. M. A. Krivoglaz, Diffuse Scattering of X-Rays and Thermal Neutrons by Fluctuational Inhomogeneities of Imperfect Crystals (Berlin: Springer: 1996).

8. B. Schönfeld, Progr. Mater. Sci., 44, No. 5: 435 (1999).

9. G. E. Ice and C. J. Sparks, Annu. Rev. Mater. Sci., 29: 25 (1999).

10. M. A. Krivoglaz, Zh. Eksp. Teor.Fiz., 32: 1368 (1957).

11. P. C. Clapp and S. C. Moss, Phys. Rev., 142, No. 2: 418 (1966).

12. P. C. Clapp and S. C. Moss, Phys. Rev., 171, No. 3: 754 (1968).

13. S. C. Moss and P. C. Clapp, Phys. Rev., 171, No. 3: 764 (1968).

14. R. A. Tahir-Kheli, Phys. Rev., 188, No. 3: 1142 (1969).

15. R. Kikuchi, Phys. Rev., 81, No. 6: 988 (1951).

16. A. Finel, Statistics and Dynamics of Alloy Phase Transformations. NATO Advanced Studies Institute, Series B: Physics. Vol.319 (Eds. P. E. A. Turchi and A. Gonis) (New York: Plenum: 1994), p. 495.

17. J. M. Sanchez, V. Pierron-Bohnes, and F. Meja-Lira, Phys. Rev. B, 51, No. 6: 3429 (1995).

18. R. Brout, Phase Transitions (New York: Benjamin: 1965).

19. I. R. Yukhnoskii and Z.A. Gurskii, Quantum Statistical Theory of Disordered Systems (Kiev: Naukova Dumka: 1991) (in Russian).

20. B. L. Gyorffy and G. M. Stocks, Phys. Rev. Lett., 50, No. 5: 374 (1983).

21. J. B. Staunton and B.L. Gyorffy, Phys. Rev. Lett., 69, No. 2: 371 (1992).

22. J. B. Staunton, Rep. Progr. Phys., 57, No. 12: 1289 (1994).

23. J. B. Staunton, D. D. Johnson, and F. J. Pinski, Phys. Rev. B, 50, No. 3: 1450 (1994).

24. D. D. Johnson, J. B. Staunton, and F. J. Pinski, Phys. Rev. B, 50, No. 3: 1473 (1994).

25. F. J. Pinski, J. B. Staunton, and D. D. Johnson, Phys. Rev. B, 57, No. 24: 15177 (1998).

26. J. B. Staunton, S. S. A. Razee, M. F. Ling, D. D. Johnson, and F. J. Pinski, J. Phys. D: Appl. Phys., 31, No. 19: 2355 (1998).

27. D. A. Rowlands, J. B. Staunton, B. L. Gyorffy, E. Bruno, and B. Ginatempo, Phys. Rev. B, 72, No. 4: 045101 (2005).

28. D. A. Rowlands, A. Ernst, B. L. Gyorffy, and J. B. Staunton, Phys. Rev. B, 73, No. 16: 165122 (2006).

29. V. Gerold and J. Kern, Acta Metall., 35, No. 2: 393 (1987).

30. F. Livet, Acta Metall., 35, No. 12: 2915 (1987). 
31. V. G. Vaks, N. E. Zein, and V. V. Kamyshenko, J. Phys. F: Metal Phys., 18, No. 8: 1641 (1988).

32. V. G. Vaks, N. E. Zein, and V. V. Kamyshenko, J. Phys.: Condens. Matter, 1, No. 11: 2115 (1989).

33. V. G. Vaks and V. V. Kamyshenko, J. Phys.: Condens. Matter, 3, No. 10: 1351 (1991).

34. V. I. Tokar, Phys. Letters A, 110, No. 9: 453 (1985).

35. T. A. Grishchenko, I. V. Masanskii, and V. I. Tokar, J. Phys.: Condens. Matter, 2, No. 21: 4769 (1990).

36. V. I. Tokar, I. V. Masanskii, and T. A. Grishchenko, J. Phys.: Condens. Matter, 2, No. 50: 10199 (1990).

37. I. V. Masanskii, V. I. Tokar, and T. A. Grishchenko, Phys. Rev. B, 44, No. 9: 4647 (1991).

38. I. Tsatskis, Phil. Mag. Lett., 78, No. 5: 403 (1998).

39. I. Tsatskis, J. Phys.: Condens. Matter, 10, No. 9: L145 (1998).

40. I. Tsatskis and E. K. H. Salje, J. Phys.: Condens. Matter, 10, No. 17: 3791 (1998).

41. I. Tsatskis, Phys. Letters A, 241, Nos. 1-2: 110 (1998).

42. R. V. Chepulskii, J. Phys.: Condens. Matter, 10, No. 7: 1505 (1998).

43. R. V. Chepulskii and V. N. Bugaev, J. Phys.: Condens. Matter, 10, No. 33: 7309 (1998).

44. R. V. Chepulskii and V. N. Bugaev, J.Phys.: Condens. Matter, 10, No. 33: 7327 (1998).

45. R. V. Chepulskii and V. N. Bugaev, J. Phys.: Condens. Matter, 10, No. 39: 8771 (1998).

46. R. V. Chepulskii and V. N. Bugaev, J. Phys. Chem. Solids, 59, No. 9: 1469 (1998).

47. R. V. Chepulskii, J. Phys. Chem. Solids, 59, No. 9: 1473 (1998).

48. R. V. Chepulskii and V. N. Bugaev, Solid State Commun., 105, No. 10: 615 (1998).

49. R. V. Chepulskii, J. Phys.: Condens. Matter, 11, No. 44: 8645 (1999).

50. R. V. Chepulskii, J. Phys.: Condens. Matter, 11, No. 44: 8661 (1999).

51. R. V. Chepulskii, Phys. Rev. B, 61, No. 13: 8606 (2000).

52. R. V. Chepulskii, J. Phys.: Condens. Matter, 14, No. 8: L193 (2002).

53. R. V. Chepulskii, J. B. Staunton, E. Bruno et al., Phys. Rev. B, 65, No. 6: 064201 (2002).

54. R. V. Chepulskii, Phys. Rev. B, 69, No. 13: 134431 (2004).

55. R. V. Chepulskii, Phys. Rev. B, 69, No. 13: 134432 (2004).

56. V. A. Tatarenko, T. M. Radchenko, and V. M. Nadutov, Metallofiz. Noveishie Tekhnol., 25, No. 10: 1303 (2003) (in Ukrainian).

57. V. A. Tatarenko and T. M. Radchenko, Intermetallics, 11, Nos. 11-12: 1319 (2003).

58. V. A. Tatarenko, S. M. Bokoch, V. M. Nadutov, T. M. Radchenko, and Y. B. Park, Defect and Diffusion Forum, 280-281: 29 (2008).

59. S. M. Bokoch and V. A. Tatarenko, Solid State Phenomena, 138: 303 (2008).

60. S. M. Bokoch and V. A. Tatarenko, Uspehi Fiziki Metallov, 11, No. 4: 413 (2010).

61. I. V. Vernyhora, V. A. Tatarenko, and S. M. Bokoch, ISRN Thermodynamics, 2012: ID 917836-1-11 (2012); doi:10.5402/2012/917836.

62. J. S. Smart, Effective Field in Theories of Magnetism (Philadelphia: W. B. Saunders Company: 1966).

63. D. Jiles, Introduction to Magnetism and Magnetic Materials (London: Charman \& Hall: 1991).

64. A. Aharoni, Introduction to the Theory of Ferromagnetism (New York: Oxford 
University Press: 2000).

65. S. V. Semenovskaya, phys. stat. sol. (b), 64, No. 1: 291 (1974).

66. S. M. Bokoch, M. P. Kulish, and T. D. Shatnii, Metallofiz. Noveishie Tekhnol., 26, No. 5: 627 (2004) (in Russian).

67. S. M. Bokoch, M. P. Kulish, V. A. Tatarenko, and T. M. Radchenko, Proc. of the $1^{\text {st }}$ International Conf. on Diffusion in Solids and Liquids-DSL-2005 (July 6-8, 2005, Aveiro), vol. 1, p. 57.

68. S. M. Bokoch, N. P. Kulish, and V. A. Tatarenko, Fundamental'nyye Problemy Sovremennogo Materialovedeniya, 4: 78 (2007) (in Russian).

69. S. H. Rahman, Acta Crystallogr. A, 49, No. 1: 56 (1993).

70. S. H. Rahman, Acta Crystallogr. A, 49, No. 1: 68 (1993).

71. S. H. Rahman and M. Rodewald, Acta Crystallogr. A, 51, No. 2: 153 (1995).

72. K. Osaka and T. Takama, Acta Mater., 50, No. 6: 1289 (2002).

73. S. Hata, S. Matsumura, N. Kuwano, and K. Oki, J. Surf. Analysis, 3: 401 (1997).

74. S. Hata, H. Fujita, C. G. Schlesier, S. Matsumura, N. Kuwano, and K. Oki, Mater. Trans. JIM, 39, No. 1: 133 (1998).

75. S. Hata, S. Matsumura, N. Kuwano, and K. Oki, Acta Mater., 46, No. 3: 881 (1998).

76. S. Hata, S. Matsumura, N. Kuwano, K. Oki, and D. Shindo, Acta Mater., 46, No. 14: 4955 (1998).

77. S. Hata, T. Mitate, N. Kuwano, S. Matsumura, D. Shindo, and K. Oki, Mater. Sci. Eng. A, 312, No. 1-2: 160 (2001).

78. U. D. Kulkarni, Acta Mater., 52, No. 9: 2721 (2004).

79. S. Lefebvre, F. Bley, M. Fayard, and M. Roth, Acta Metall., 29, No. 5: 749 (1981).

80. P. Cenedese, F. Bley and S. Lefebvre, Mat. Res. Soc. Symp. Proc., 21, 351 (1984).

81. X. Jiang, G. E. Ice, C. J. Sparks, L. Robertson, and P. Zschack, Phys. Rev. B, 54, No. 5: 3211 (1996).

82. G. E. Ice, C. J. Sparks, A. Habenschuss, and L. B. Shaffer, Phys. Rev. Lett., 68, No. 6: 863 (1992).

83. J. L. Robertson, G. E. Ice, C. J. Sparks, X. Jiang, P. Zschack, F. Bley, S. Lefebvre, and M. Bessiere, Phys. Rev. Lett., 82, No. 14: 2911 (1999).

84. F. Bley, Z. Amilius, and S. Lefebvre, Acta Metall., 36, No. 7: 1643 (1988).

85. S. Lefebvre, F. Bley, M. Bessiere, M. Fayard et al., Acta Crystallogr. A, 36, No. 1: 1 (1980).

86. G. L. Squires, Introduction to the Theory of Thermal Neutron Scattering (Cambridge: Cambridge University Press: 1978).

87. S. W. Lovesey, Theory of Neutron Scattering from Condensed Matter (New York: Oxford University Press: 1984), vols. 1, 2.

88. Neutron Scattering from Magnetic Materials (Ed. T. Chatterji) (Amsterdam: Elsevier: 2006). 